$x^{2}+x^{2}=$

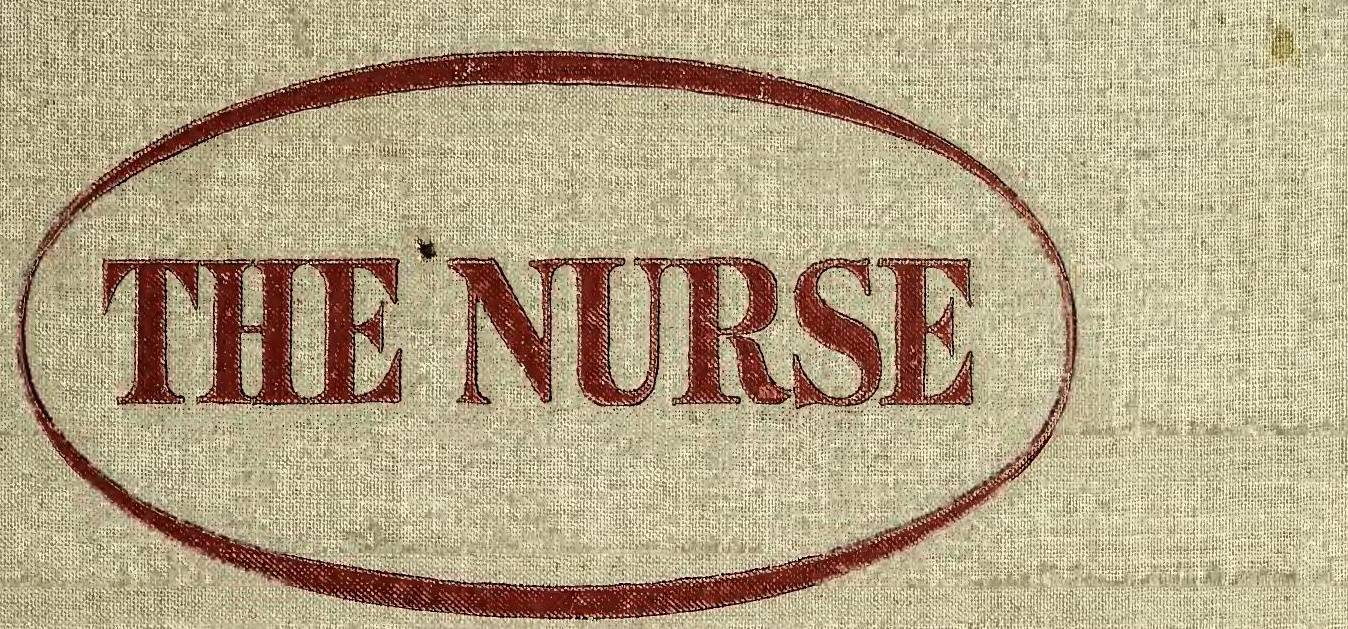

(2)

(6) (4): 

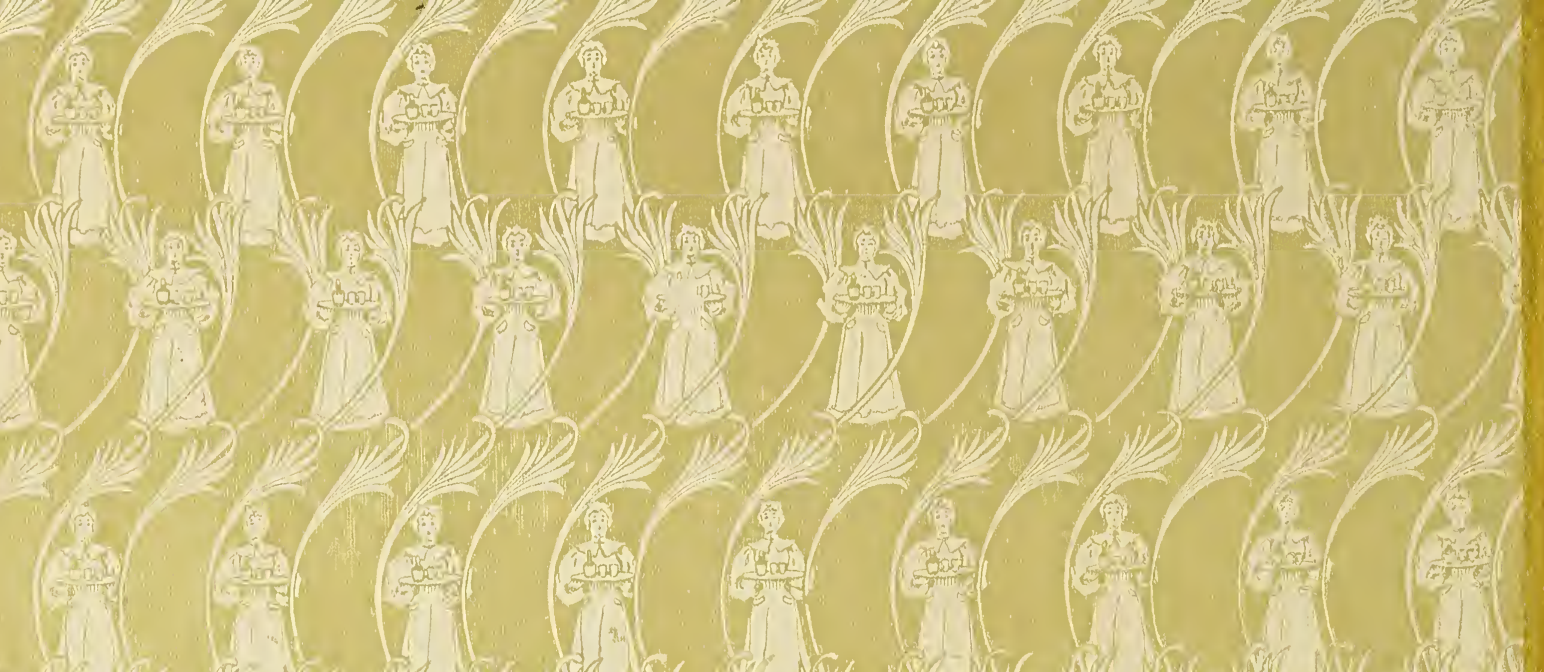

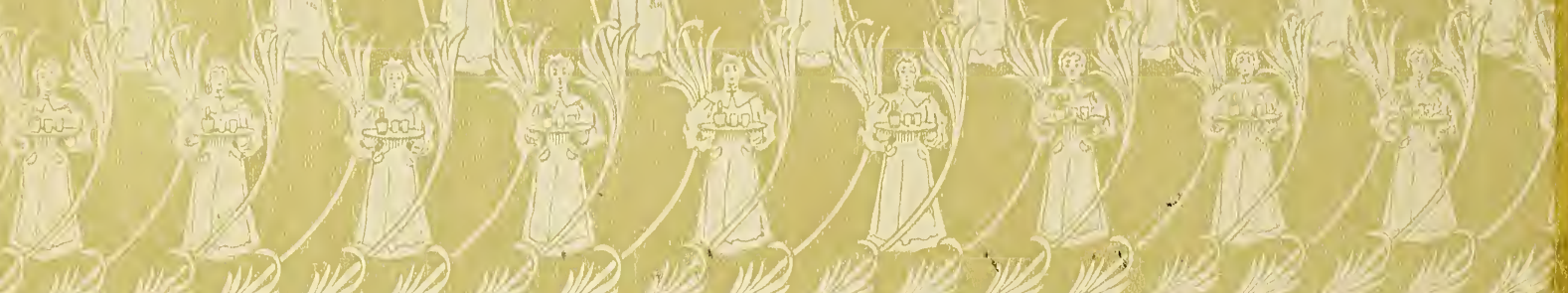

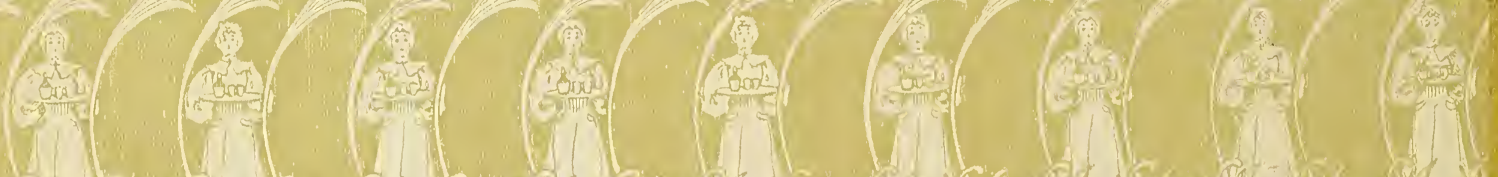

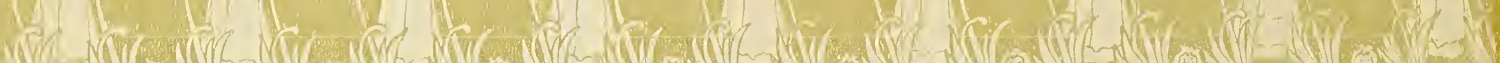

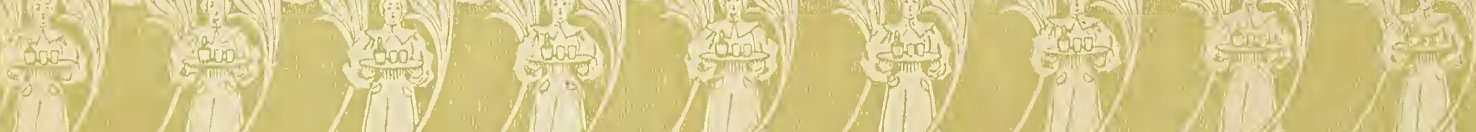

(2) 102 (1102 110
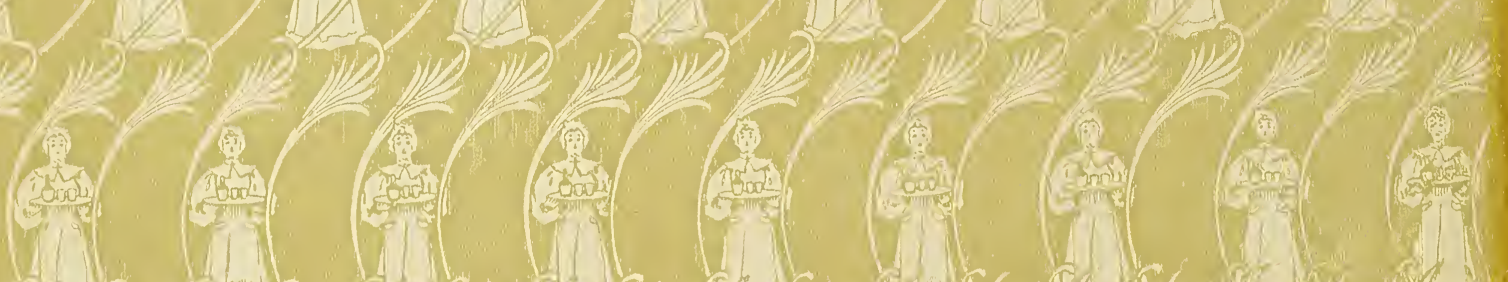

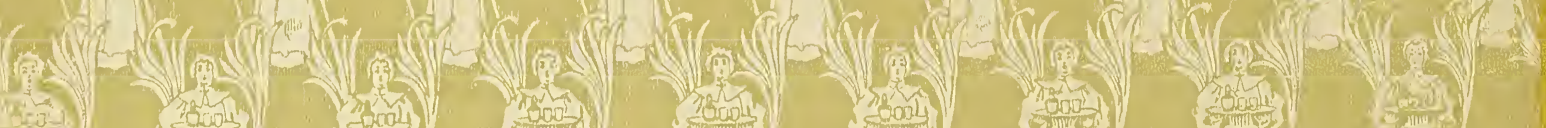

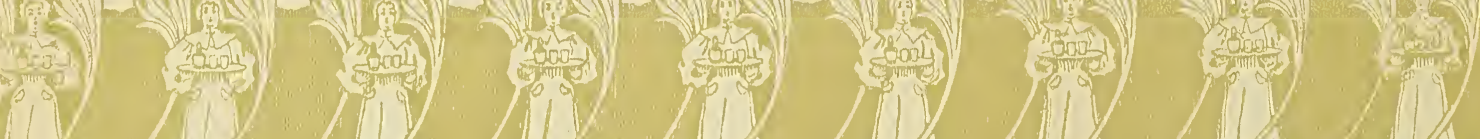

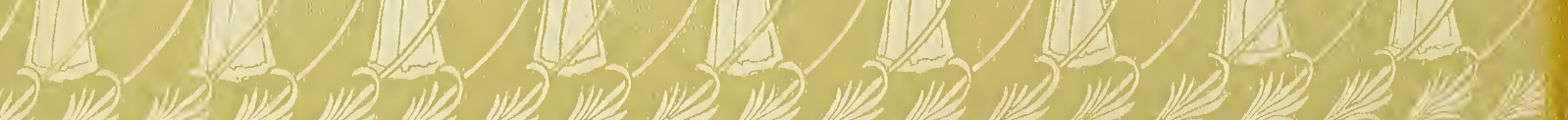

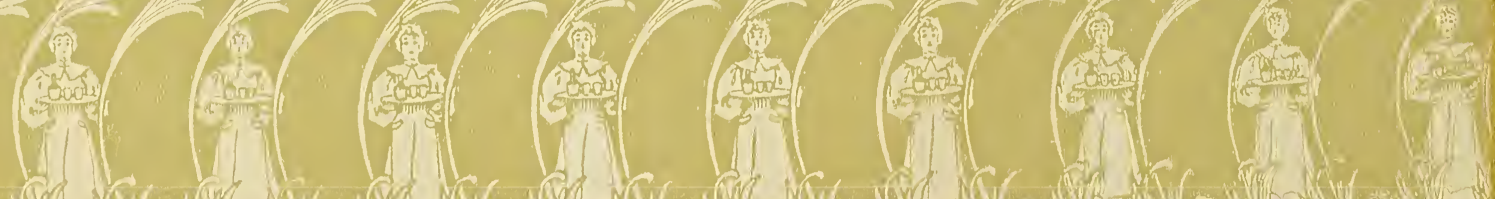

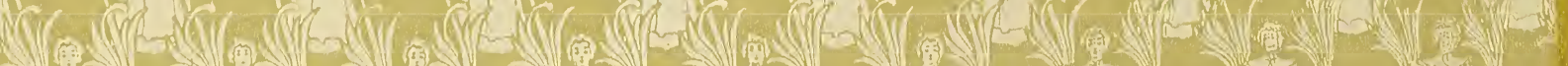

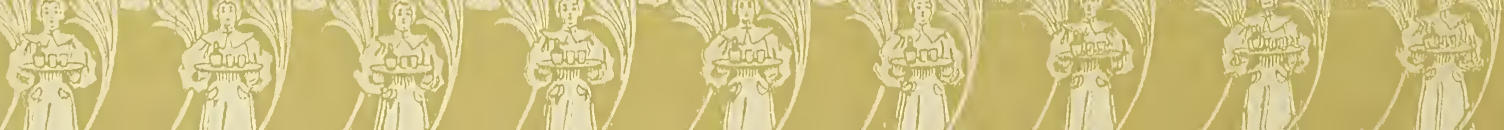




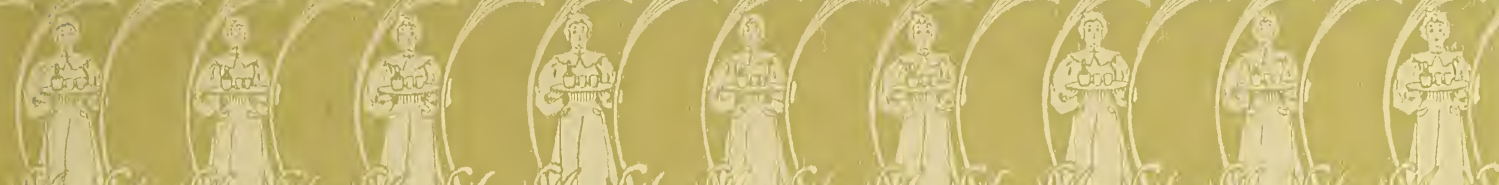

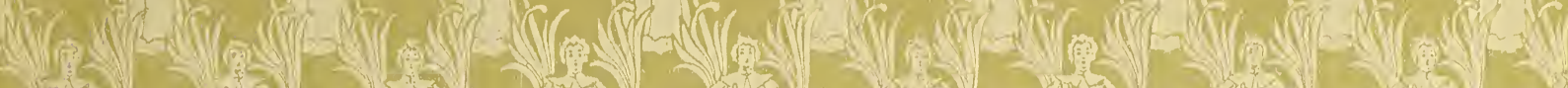

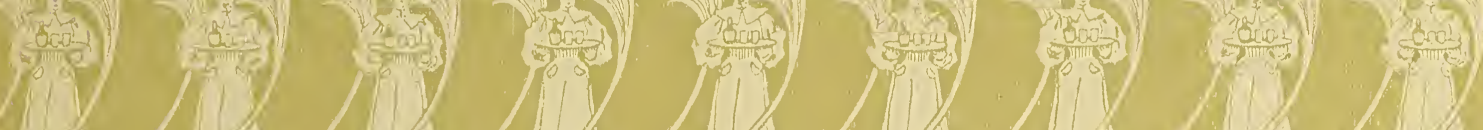

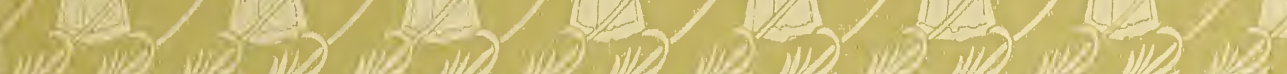

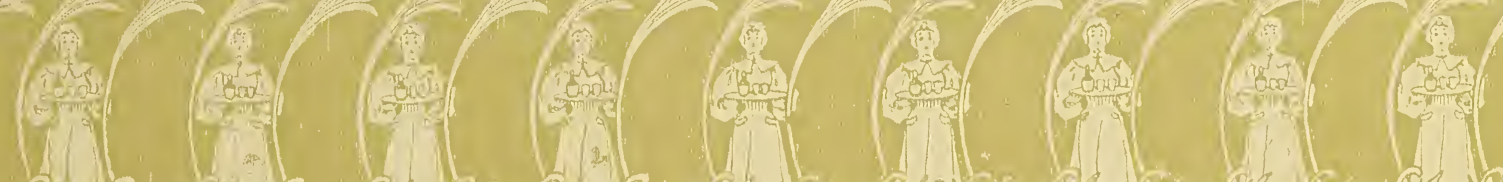

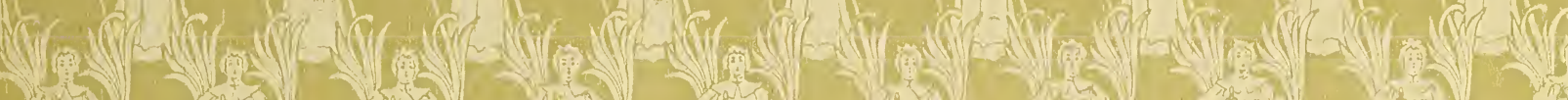

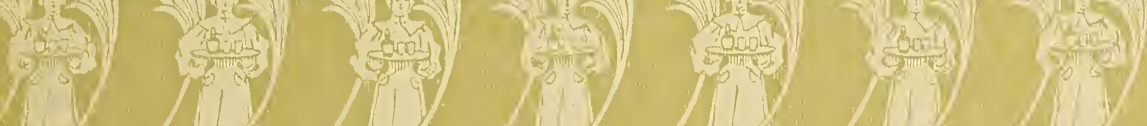

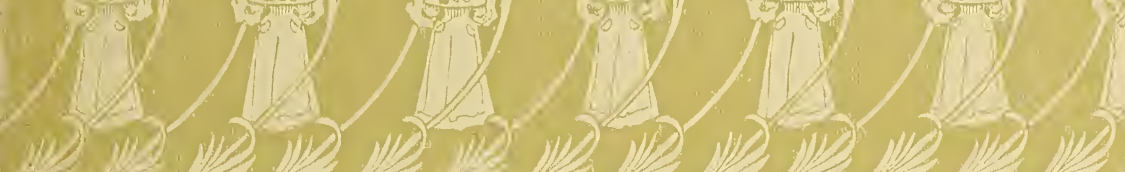

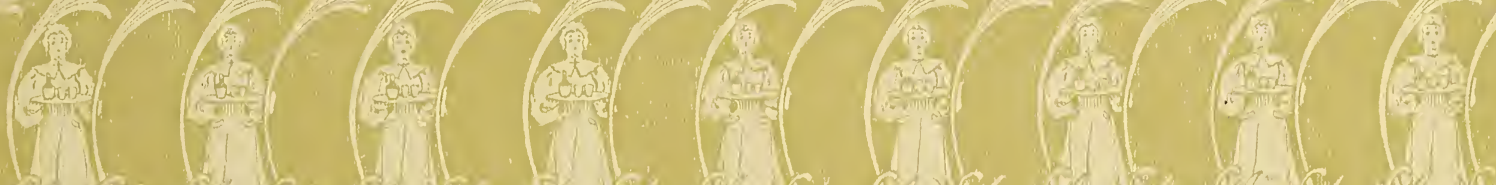

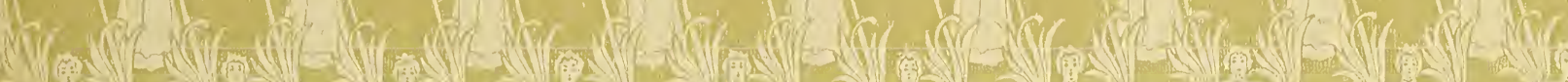

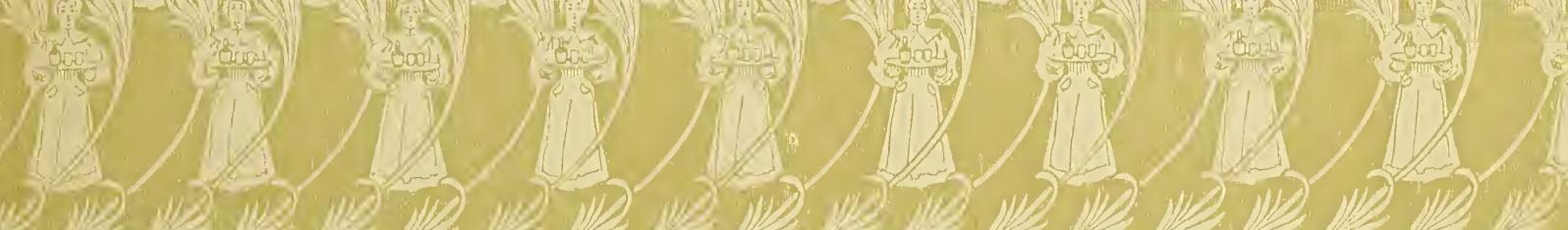

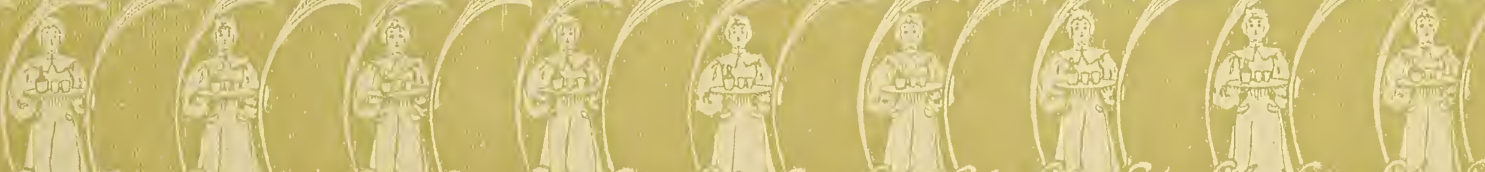

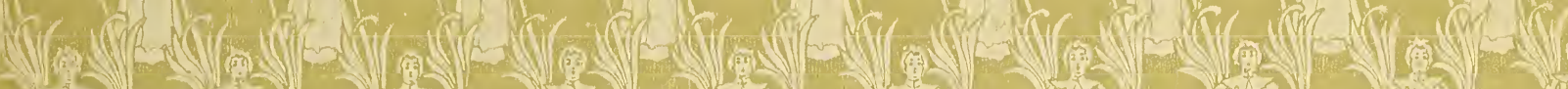

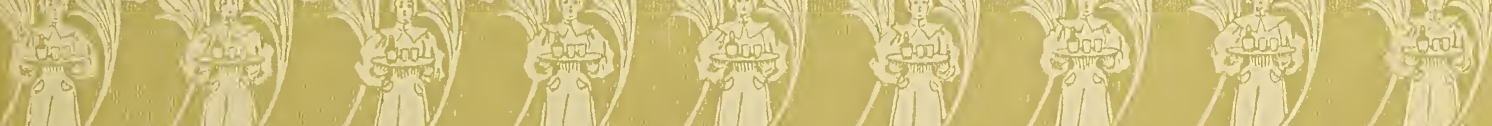

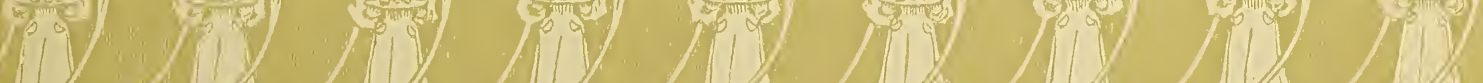
(2)

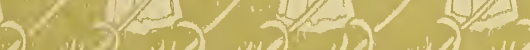
(2) 


Co those people who silare our many sorrows and but few of our blessings, sae Cbe Durses of Jimerica, this volume is respectinlly and gratefuny dedicated. 


\section{THE NURSE}

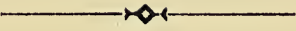

PRESENTED bY

PABST BREWING CO。

Manufacturers Pabst Malt Extract,

The 'Best' Tonic

Milwaukee, Wis. 


\section{Copyright 1896 by PABST BREWING CO.,}

Milwaukee, Wis.

Published by KING-Fowle-MCGeE-Co., Milwaukee. 


\section{PREFACE.}

This little volume which we place in your hands, with most sincere appreciation of your work and calling, is by no means a book of advice. It simply designs to suggest to you some few things you may not have met with in your experience, or have overlooked or forgotten, and which may "come handy" in an emergency, or give a word of help in time of doubt. If you have been through a regular course of training many of the ideas here expressed may still be found of much value to you, especially when you remember that no one on earth knows everything, and that from the humblest sources sometimes come the richest blessings. If you have had little or no training, we are confident you will be glad to read these pages, since they will carry with them considerable information, on which you can positively rely, and can also act upon with confidence in safety and with success. The suggestions have been culled from the best possible works on the divine art of nursing, and have the sanction and approval of eminent physicians.

Cordially yours,

THE EDITOR. 



\section{The Expectant Inother.}





\section{THE EXPECTANT MOTHER.}

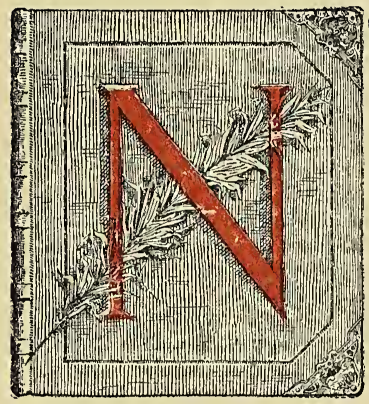

better beginning to this volume and this chapter can be made than by quoting the magnificent words of the good gray poet, Walt Whitman. He, the celebrator of the human form divine, gave it its first and finest poetic recognition.

The

human

form divine.

"I am the poet of the woman the same as the man;

And I say it is as great to be a woman as to be a man,

And I say there is nothing greater than the mother of men.

The man's body is sacred and the woman's body is sacred.

No matter who it is, it is sacred.

Be not ashamed, women, your privilege encloses the rest and is the exit of the rest;

You are the gates of the body and you are the gates of the soul."

We would follow the fine example of the Homer of America, in approaching the subject

Gates

of

the

body. 
Happy
expectation.

of the care and nursing of the human body from infancy to old age, with that reverent sense of its sacredness which comes from the Divine declaration:

"And God made man in His own image."

We seldom find a young woman in the happy expectation of becoming the mother of a little child, who does not at once begin to provide for its comfort. The beautiful trousseau is often as carefully and almost as expensively arranged as that of a bride.

From the beribboned and laced cap to the tiny socks, everything is provided that money and taste can afford.

But when we ask the dear little woman what

What should I provide?

A

clever thing. she has provided for herself, she looks in a sort of blank surprise and asks: "Why, what should I provide? Don't the nurse and doctor have things?" They do not have the things that are invaluable on such occasions, and if you have been engaged to go to her bedside when she most needs you, it will be a kind and proper thing for you to suggest to her not to be quite neglectful of her own comfort while doing so much for her baby. In fact, it would be a clever thing for you to have a written or printed list of the things you will otherwise probably find lacking when you arrive at the house, possibly at the last moment, and as women usually carry out the suggestions of their nurses, you will thank your lucky stars and she hers, that nothing has been forgotten. In the first place use: 
Old sheets.

Old towels, soft and thin. Bath towels.

Sponges of two sizes, one for face and hands, the other for legs and feet.

A four-quart syringe, which is better than a fountain syringe of less dimensions, for many reasons.

A first-class syringe.

Plenty of absorbent cotton.

A square of rubber sheeting, single width.

Two old blankets, one to go over the rubber sheet; the other to cover the patient in many ways and at many times. These should be single and easily handled.

One old comfortable, to be folded under the patient; it may have to be thrown away.

One package washing soda.

One bottle ammonia.

One paper basin, so much better than heavy and slippery china.

One bed-pan, according to preference.

Two short nightgowns.

Nobody nowadays seems to be provided with these garments, which were always used by our grandmothers in sickness and which are positively the best and most convenient for such occasions. They should have a pocket for the handkerchief, and then you will not have to search for it thirty-three and a half times a day.

Bandages of soft, unbleached linen. Double is best. They should be wide enough to come down to the great trochanters and up to a place two inches above the umbilicus. The length

The

list

of

things.
Best

and most convenient. 
Old

soft cloth.

Sacque.

Warm

flannel.

Unbleached muslin.

Disinfectant.

Carbolic.

Rug. should fit the woman before she became pregnant. In usual cases they might be made fifty inches long.

Napkins of old soft cloth, rolled with some absorbent cotton in the center and stitched with long basting stitches, can be used and then burned. Some recommend cheesecloth, but many patients are chafed by it. Pads made of soft cheesecloth and filled with a layer of absorbent cotton to place under the napkin save a great deal of washing and cost no more. They should be a foot square. Burn them up.

A sacque is better than a shawl, cape, nightinggale or wrap of any kind, because it does not expose the sides. If made very broad in the back without a seam and gathered into the neck with big armsizes it will be perfectly comfortable and easy to get on and off.

Warm flannel goods are best, excepting in very hot weather.

Two or three yards of soft unbleached muslin for breast bandages will be needed. A six-tailed bandage is best. Tear down the first two tails to within three inches of the others, and these, passing over the shoulders and fastening to the others, which will be adjusted over the breast, will keep the whole bandage in place.

A disinfectant and antiseptic of some sort are always necessary.

Carbolic 1-30, Platt's Chlorides, or Permanganate of Potash will do.

Have a rug or linen for the protection of the carpet, that can be placed by the side of or un- 
der the whole bed, or a square of old carpet which can be thrown away if soiled. Sometimes a beautiful carpet is ruined for lack of this forethought.

A paper pail or tub should be at hand into Pail. which to throw soiled linen.

A small yard-high clothes-horse for drying linen takes up but little room and is almost invaluable.

A pair of warm wool bed-shoes and a pair of warm stockings should be provided, as the patient may become chilly.

1 bottle alcohol for bathing.

1 bottle lavender salts.

1 bottle vaseline.

1 box cold cream.

A laxative of some kind should always be at hand, and the bowels should be kept free and regular.

A hotwater bottle or a "stone," but far better than either, a Japanese "kawara" or "hot-box" with fuel, one stick of which will burn five hours and heat the whole bed, or comfort and relieve pain in any place, will be found a great blessing. Fifty cents will provide box and fuel.

For at least six weeks before parturition a bottle of Pabst Malt Extract, The Best Tonic, should be faithfully taken each day, for the sure and sweet secretion of plenty of milk, for securing good digestion, for giving vitality and strength to the child without great fat and weight, for sound sleep, calm nerves, to over-

Clothes-

horse.

Bed-shoes.

Salts,

etc.

Laxative.

Hotwater bottle.

Best

Tonic. 
come nausea, and to give a free and easy delivery from a well-toned and healthy system.

Faith in God, belief in the orderliness of the Confidence. processes of nature, confidence in the average of good and healthful births, should be instilled into the mind from the outset, and carried to the end.

With these preparations, plenty of mild exercise, fresh air day and night, the cultivation of cheerfulness and the love and observation of beauty, the reading of pleasant books, the avoiding of the thought of unpleasant things, and

Happy

daily the doing one's duty in happy daily expectation expectation.

The

first

cry. of the coming blessing, will bring the little one into the world with little pain to the mother and with a fine constitution and agreeable temper.

Doubtless the expectant mother strains her ears for the first cry of her infant, which will assure her that the little one is alive, and when the sound is heard and she knows she is a mother indeed, a sense of relief unspeakable will pass over her. The so-called cry proper of the newly-born always takes place during expiration (out-breathing); sometimes a second cry is noticed, a repetition, but it is neither so strong nor so prolonged as the first. The first cry of the newly-born, which is probably due to the disagreeable impression the air makes upon the exterior surface of the body, is always sustained and easy with infants born alive. (The lungs perform the respiratory function for the first time, producing the "cry" by inspiring oxygen and expiring carbonic acid.) 
And when this first utterance of human nature breaks the silence, asserting the coming into the world of a new-born soul, one involuntarily remembers the beautiful words of welcome given by the English Wordsworth in his splendid new-born soul.

"Ode on the Intimations of Immortality:"

"Our birth is but a sleep and a forgetting:

The soul that rises with us, our life's star Hath had elsewhere its setting,

And cometh from afar.

Not in entire forgetfulness,

And not in utter nakedness,

But trailing clouds of glory do we come, From God, who is our home." 



\section{The IInfant and IIIother.}





\section{THE INFANT AND MOTHER.}

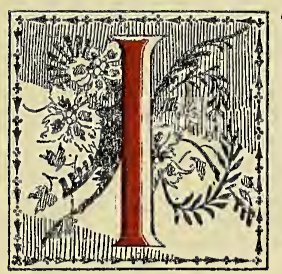

welcomed into weighed and displayed, will probably take an idea in its tiny pate that it is time the new place he has come to should afford him a meal. He don't know where to get it, or how to take it, but he begins to "nosel around" and fret, giving evidence of his inward craving. He should nurse at least twice a day until there is a sufficient flow of milk. There is always more or less colostrum, which is slightly laxative and altogether suitable for the infant's digestion. The mother should be placed as comfortably as possible on her side and a pillow tucked at her back, so that she rests upon it and does not have to hold herself up. The nipple having been washed with tepid water, the baby is placed in a perfectly comfortable position and taught to nurse. Of course the little thing does not know how, he never did it before, yet $\mathrm{Na}$ -
Safely welcomed.

Taught

to

nurse. 
Baby

would not nurse.

Thrives on mother food.

Fresh

air and light. ture within him gives him an inkling, and although sometimes the greatest care and patience will have to be used, if persisted in it should always be successful. There should not be a case of bringing up by hand because "baby would not nurse," if the nurse conscientiously does her duty and the milk which is offered to his palate is rich, sweet, healthy and delicious.

Nursing the child helps to contract the uterus and restore the mother to a normal condition. If her supply is ample and the baby thrives on it no other food should be given it, especially in hot weather. Be careful not to permit the infant to nurse if the mother is fatigued or over-heated. Cool both with a sponge-bath of tepid water with a little alcohol and rosewater added. In ten minutes both will be in proper condition. Keep the rooms sweet and clean, cool enough in summer and warm enough in winter to give the greatest amount of comfort and vitality. Do not be afraid to have the window open at night. Screen it with a shawl tacked up, if you haven't anything better, but let in fresh air. Never have the bed of the mother or the crib of the infant face the light, even if you have to turn the bed head to the window, which, by the way, makes a fine screen of itself. Never let the light pour straight into the eyes of either, whether natural or artificial, and beware of having a light burning over the top of the baby's head. There is nothing more irritating to the brain than the rays of a bright light falling directly on the top of the 
head. Sound sleep is impossible under any of these conditions and the eyes may be permanently injured.

We do not presume to attempt to direct a competent nurse how to wash and dress a little child, nor to suggest to an experienced midwife the various details in the care of the mother, Wash and dress. but here are two or three points which may not always be carefully heeded which may inform a young mother. Premature and feeble children require more warmth, more frequent feeding and in smaller quantities than others. If the child's breasts become swollen, do not worry. Let them alone. Warmth and gentle pressure and easy massage of the abdomen, rubbing from left to right, are harmless and useful remedies in colic. After the child has eaten, let it lie upon your shoulder and give it a little motion until it belches wind. If hiccoughs ensue do not be alarmed-both are natural and help digestion. The child's average gain in weight should be at least one quarter of a pound per week during the first five months of its life. If his nutriment comes entirely from the mother, her choice of food should be regulated by its effect upon him.

A varied, nutritious diet should be given her, avoiding what she knows "hurts her," but not differing much from her ordinary diet. She has a right to eat what she likes and her infant will be better satisfied if she has it. Still, one must remember that over-feeding has a bad effect, for only the amount digested will make milk; the rest is a clog.

Hiccoughs are natural.

Nutritions diet. 
Improper

for

a

mother.

A hungry baby.

Deficient in quantity.

Use

Best

Tonic.
There are, of course, cases where it is improper for a mother to nurse her child at all. If she has little maternal instinct and is lacking in consideration for her child, so that she indulges in outbursts of temper, hysterics, etc., bringing on nausea, exhaustion, neuralgia or sleeplessness, or in cases of hereditary disease, the better way is to bring up the baby on a bottle or have a wet nurse-and some physicians honestly think in the latter case an unmarried woman, the mother of a "love child," is the best. Never allow a baby to be hungry! A cross baby is almost invariably a hungry baby. Are not you out of temper when your "belly is empty" and don't you cry, "Pray, mamma, give me some dinner!" There are "four and twenty" hours in the day, and at least every two of them, if the child is awake, he should "have a snack," if nothing more than "pot-luck." "But," writes Clara A. Penniston in "The Trained Nurse" for April, 1893, "in spite of all we can do, the milk of city-bred mothers is generally deficient in quantity or quality, and we are very often, after the third week, compelled to supplement the breast with the bottle. The indications for this are, baby does not sleep soundly, crying and constantly hunting for his dinner and when at the breast grumbles in a curious way."

The dear lady could not have been fortunate enough to have used Pabst Malt Extract, The Best Tonic, during her experience, or she could not have written as above. The milk of city mothers, both in quality and quantity, can be 
made as acceptable, palatable, nutritious, sleepprovoking, strengthening and sweet temper insuring as that of the bonniest country lass or native squaw. She has only to prepare for it beforehand with the constant use of this fine Malt Extract, and no "curious grumbling," but an eager and happy sucking away will be noticed after the little one has learned its first lesson of how to take hold! Meantime, how about the mother? The vital fluid is needed to make milk, and to make rich milk, rich, clean blood is necessary. Therefore, do not have your patient rise from her bed too soon, or before you are perfectly sure the uterine wound is wholly healed.

The Board of Health has recommended to the attention of thoughtful mothers and nurses some especial rules for the care of infants during hot weather, which is usually the most critical time for them: Bathe the child once a day in luke-warm water, and if it is feeble sponge it all over twice a day with luke-warm water and vinegar. Avoid all tight bandaging. Have light flannel as the inner garment and the rest of the clothing light and cool and so loose that the child can have free play of its limbs. At night undress it, sponge it and put on a slip. In the morning remove the slip, bathe the child and dress it in clean clothes. If this cannot be afforded thoroughly air the day clothing by hanging it up at night. Use clean diapers and change them often. Never dry a soiled one, nor leave a soiled one ten minutes in the room where mother and child are living. "Never use one
Palatable, nutritious.

Bathe

the

child.

Change

them often. 
for a second time without washing." Use Fuller's earth to prevent chafing, or if not, common corn starch, which is better than prepared "powders." The infant should not sleep in the

In

a

cradle.

Never

give

any

spirits.

Fresh

and

clean.

Cholerainfantum. bed with the mother, but in a cradle or crib by itself, and be early taught to go to sleep without any attention of mother or nurse. See that the little one is perfectly comfortable and then let it cry, if it will, for a night or two, and if you pay no attention to it (unless it seems to actually be injuring itself with crying) the third night it will accept the conditions and go to sleep quietly. This will be a comfort and relief to the mother during all its infancy and childhood, and while it may seem "cruel," it is a tender and wise cruelty. Without the advice of the physician never give any spirits, cordials, carminatives, soothing syrups or sleeping drops. Thousands of children die every year from these poisons. If the child frets and does not sleep it is either hungry or ill. Never quiet it by candy or cake, for they are the common causes of diarrhœa and other troubles. Whenever it seems to suffer from the heat let it drink freely of water which has been boiled and cooled by ice. It is excessive heat which destroys the liver of young infants. Be positive that the nursing bottle and nipple are fresh and clean. Illness comes very often from a sour bottle or nipple.

Dr. Geo. S. Cahill, in an article on "Summer Diarrhœa in Children," says: "In all cases of cholera-infantum or gastro-enteritis of any degree of severity, rest is the best treatment, 
and takes the place of much unnecessary medication. When an infant is suffering from any form of gastric or intestinal disturbance, it is well to have a period of complete abstinence from food, varying in length according to the gravity of the case. This period may be wisely occupied in freeing the digestive canal of its irritating contents, which, undigested, act as foreign bodies upon the diseased mucous surface. The sooner the entire alimentary canal is freed from these irritants the better. To lock them up in the bowels by the administration of opiates (to ease the child) is the worst possible practice. Rest, complete rest, can only be obtained for the diseased part by the emptying and cleansing of the tract and the temporary withdrawal of food."

As regards other diseases, the major part of the ills of infantile life come from starvation.

Another thing, babies need a great deal of water, and they seldom get enough of it. Every thoughtful, careful nurse and mother will accustom the child to take both cold and hot water from a perfectly clean bottle, for it is the best fluid to quench thirst and a large quantity of it is required to carry on the functions of the system.

The following short article by F. C. Hill in the Baby's Department of The Trained Nurse, seems to us of very great value in the indication of "What Ails the Child?" so often spoken. He calls it "The Cry of the Children." "The cry of children in pneumonia and capillary bronchitis is moderate, peevish and muffled, as if a door were shut between the child and the hearer.

The sooner the better.

Other diseases.

Water.

The cry. 
Usually hunger.

The cry of croup is hoarse, brassy and metallic, with a crowing inspiration. That of cerebral disease, particularly hydrocephalus, is short, sharp, shrill and solitary. Marasmus and tubercular peritonitis are manifested by moaning and wailing. Obstinate, passionate and long continued crying tells of earache, thirst, hunger, original meanness or the pricking of a pin. The pleuritic is louder than the pneumonic, and is evoked by moving the child or on coughing. The cry of intestinal ailment is often accompanied by wriggling and writhing before defacation. Exhaustion and prostration are manifested by a whine. Crying only, or just after coughing, indicates pain caused by the act. The return or inspiratory part of the cry grows weaker toward the fatal end of all diseases, and the absence of crying during disease is often of graver import than its presence, showing complete exhaustion and loss" of power. Loud screaming sometimes tells of renal gravel."

The following rules have been prepared by the Obstetrical Society of Philadelphia, to be fol-

Vomiting and prostration. lowed if the baby is suddenly attacked with vomiting, purging and prostration. Send for a doctor at once. In the meantime put the child for a few minutes in a hot bath, then carefully wipe it dry with a warm towel and wrap it in warm blankets. If its hands and feet are cold, bottles filled with hot water and wrapped in flannel should be laid against them. A mush poultice or one made of flaxseed meal, to which onequarter part of mustard flour has been added, or 
flannels wrung out in hot vinegar and water should be placed on the belly. Five drops of Poultice. brandy in a teaspoon of water may be given every ten or fifteen minutes, but if the vomiting persists give the brandy in the same quantity of milk and lime water.

This treatment will prove harmless and effective in almost any sudden emergency, until a physician can arrive.

Harry R. Purdy, M. D., New York, gives these excellent hints: (See table, page 29.)

"Very large, robust infants may require more, and small or delicate ones less than the above indicated.

That is to say, if an infant of twelve weeks is no heavier than the ordinary infant is at six weeks it should be fed as though it were a sixweeks' infant. On the other hand, if a sixweeks' infant is as heavy and as hungry as a twelve-weeks' infant it should be fed as much as the latter is. But these are exceptions.

The right way to make barley water is as follows:

\section{"BARLEY WATER.}

Take of barley in the whole grain one ounce, wash it with cold water, then boil it with about a half pint of water for five minutes and throw this liquid away. Now add to the barley two pints of boiling water and boil down to one pint, strain and keep the liquid in a cool place or on the ice till needed when, like the milk, it should be slightly warmed.

If it suffer with prickly heat, a tablespoonful

More

or

Ordinary

and

extraordinary. 
Prickly heat.

Parks or water.

Cleanliness. of baking soda may be added to the bath, and, after drying the skin, dust it lightly with talcum, powdered talc or French chalk.

The baby should have plenty of fresh air; and during the heated term mothers are advised to take their children to the parks, or on the water, as frequently as possible."

The nurse should wear plain washable gowns, and after an obstetrical case, should change it at once. She should remember the weakness and helplessness of both mother and child, and regard with reverent awe the God-ordained operation of nature, by which the race is issued into the world. Cleanliness, cleanliness, "from A to $Z$, from Genesis to Revelations," should be the "godliness," which will aid in the success and safety of every case of obstetrical and infant nursing. 
TABLE

Fbowing thow and vouben to Jfeed or Wurge the Ziverage Infant.

\begin{tabular}{|c|c|c|c|}
\hline $\begin{array}{c}\text { Infant's } \\
\text { Age. }\end{array}$ & $\begin{array}{c}\text { How often } \\
\text { to feed } \\
\text { or nurse. }\end{array}$ & \begin{tabular}{|} 
No. of \\
feedings \\
in 24 \\
hours.
\end{tabular} & $\begin{array}{l}\text { Quantity at each Feeding and how to dilute } \\
\text { the milk. } \\
\text { (One ounce equal to two table- or eight tea- } \\
\text { spoonfuls.) }\end{array}$ \\
\hline $\begin{array}{l}\text { First } \\
\text { week. }\end{array}$ & $\begin{array}{c}\text { I } 1 / 2 \\
\text { hours. }\end{array}$ & IO & $\begin{array}{l}\text { One ounce or two tablespoonfuls pre- } \\
\text { pared as follows: } \\
2 \text { teaspoonfuls milk. } \\
5 \text { teaspoonfuls water that has been } \\
\text { boiled and cooled. } \\
\text { I teaspoonful lime water. }\end{array}$ \\
\hline $\begin{array}{c}\text { I to } 3 \\
\text { weeks. }\end{array}$ & $\begin{array}{c}2 \\
\text { hours. }\end{array}$ & 8 & $\begin{array}{l}\text { One and one-half ounce or three table- } \\
\text { spoonfuls: } \\
3 \text { teaspoonfuls milk. } \\
8 \text { teaspoonfuls boiled water. } \\
\text { I teaspoonful lime water. }\end{array}$ \\
\hline $\begin{array}{r}3 \text { to } 6 \\
\text { weeks. }\end{array}$ & $\begin{array}{c}2 \mathrm{I} / 2 \\
\text { hours. }\end{array}$ & 7 & $\begin{array}{l}\text { Two ounces or four tablespoonfuls: } \\
51 / 2 \text { teaspoonfuls milk. } \\
9 \text { teaspoonfuls boiled water. } \\
\text { I } 1 / 2 \text { teaspoonfuls lime water. }\end{array}$ \\
\hline $\begin{array}{c}6 \text { to } 9 \\
\text { weeks. }\end{array}$ & $\begin{array}{c}3 \\
\text { hours. }\end{array}$ & 6 & $\begin{array}{l}\text { Three ounces or six tablespoonfuls: } \\
21 / 2 \text { tablespoonfuls milk. } \\
3 \text { tablespoonfuls boiled water. } \\
2 \text { teaspoonfuls lime water. }\end{array}$ \\
\hline $\begin{array}{l}9 \text { to } 12 \\
\text { weeks. }\end{array}$ & $\stackrel{3}{\text { hours. }}$ & 6 & $\begin{array}{l}\text { Four ounces or eight tablespoonfuls: } \\
4 \text { tablespoonfuls milk. } \\
31 / 2 \text { tablespoonfuls boiled water. } \\
2 \text { teaspoonfuls lime water. }\end{array}$ \\
\hline $\begin{array}{l}4^{\text {th th to }} \\
6 \text { th } \\
\text { month. }\end{array}$ & $\stackrel{3}{\text { hours. }}$ & 6 & $\begin{array}{l}\text { Five ounces or ten tablespoonfuls: } \\
71 / 2 \text { tablespoonfuls milk. } \\
2 \text { tablespoonfuls boiled water. } \\
2 \text { teaspoonfuls lime water. }\end{array}$ \\
\hline $\begin{array}{l}6 \text { ch to } \\
\text { Ioth } \\
\text { month. }\end{array}$ & $\stackrel{3}{\text { hours. }}$ & 6 & $\begin{array}{l}\text { Six ounces or twelve tablespoonfuls: } \\
9 \text { tablespoonfuls milk. } \\
2 \text { tablespoonfuls boiled water. } \\
\text { I tablespoonful lime water. }\end{array}$ \\
\hline $\begin{array}{l}\text { Ioth to } \\
\text { I2th } \\
\text { month. }\end{array}$ & $\begin{array}{c}31 / 2 \\
\text { hours. }\end{array}$ & $\begin{array}{l}5 \\
\text { or } \\
6\end{array}$ & $\begin{array}{l}\text { Eight ounces or sixteen tablespoonfuls } \\
\text { or one tumblerful : } \\
\text { Add to this only I tablespoonful lime } \\
\text { water. }\end{array}$ \\
\hline $\begin{array}{l}\text { reth to } \\
\text { I8th } \\
\text { month. }\end{array}$ & $\stackrel{4}{4}$ & $\begin{array}{l}4 \\
\text { or } \\
6\end{array}$ & $\begin{array}{l}8 \text { ounces milk with perhaps one of } \\
\text { the prepared foods, meat juice and yolk } \\
\text { of egg; and when baby has } \mathbf{1 6} \text { teeth } \\
\text { it may also have bread and butter, } \\
\text { cracker victuals, mashed potatoes and } \\
\text { gravy, and may suck a piece of beef } \\
\text { or chicken bone. But milk must be } \\
\text { the principal food. It must not have } \\
\text { fruits, tea, coffee or beer, etc. }\end{array}$ \\
\hline
\end{tabular}



Wouth in JBoth Feres. 



\section{YOUTH IN BOTH SEXES.}

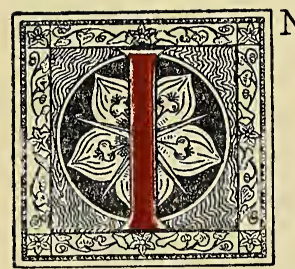

$\mathrm{N}$ other days when children were taken ill with any of the children's diseases it was presumed that the mother, grandmother, aunt or all together, were quite capable of nursing and attending upon the child, and very likely many a child died from their ignorance and inexperience. Love and tenderness go a great way, but skilled, intelligent and faithful nursing by one whose affections are not involved, is certainly more practical and sometimes proves more successful.

Judgment in care of the sick of a household is often lacking. Over-solicitude frequently renders a friend or relative unfit to take upon themselves the duties, which often involve the sight of great suffering and pain which cannot at the moment be relieved.

The system of special training of those who care for the sick has brought about a great change. Through the painstaking attention of the bedside attendant the efficiency of medicinal treatment has been greatly increased and the mortality has diminished.

$$
\begin{aligned}
& \text { As } \\
& \text { it } \\
& \text { used } \\
& \text { to } \\
& \text { be. }
\end{aligned}
$$

Judgment often lacking. increased. 
Has

become

a

necessity.

Again, with convalescence the care does not abate, for the successful issue of the illness is a matter of especial interest to the enthusiastic nurse. "In private practice," writes Frank E. West, M. D., "the advent of the skilled nurse has accomplished great good. In cases of serious sickness she has become a necessity. Without her help the attending physician feels very much handicapped. When the doctor calls he receives an intelligent account of all that has occurred since his last visit. Furthermore, it often happens that emergencies arise suddenly. Many of these the competent nurse is perfectly capable of meeting. She at least knows how to act until the arrival of the physician. Her presence may make all the difference between life and death to the one intrusted to her care."

There are unfortunately, besides the various diseases which attack children, as measles, mumps, whooping cough, diphtheria and the like, especial illnesses and derangements which come to boys and girls at the ages between thirteen and fifteen. The old-fashioned method was one of extreme and false modesty about these inevitable and most seriously critical periods in human life, and the father and mother, silent and ashamed of a God-planned function, would let their promising lad or bright girl

A word of information. come to the development of man and womanhood without a word of information, warning or advice.

The result of this silence has been to throw a youth or maiden upon his or her own natural 
impulses without the direction of intelligence or the aid of reason, and human wrecks, instead of strong and vigorous men and women, have disappointed the ambitions and killed the pride of the parents. Many such cases, to-day, however, are placed in the hands of skilled and trained nurses, to be restored, if possible, by vigilance and care to a normal condition. On meeting the patient we often find a pale, melancholy, retiring or seemingly effeminate young fellow, with a slinking eye, a weak memory, a love of solitude and with bad digestion, no appetite and very often a distinct craze over some subject, or a state of stupidity pitiful to behold.

These symptoms, not so prominent in the young girl, are nevertheless easily detected, and the disarrangement, overflow, ceasing altogether, great pain or other intense rebellion of nature against being meddled with, will require the utmost oversight to relieve, to assist, to conserve and to reform. As in almost every illness (for this bad state of things is an illness, and often due to the neglect of others rather than to the unwisdom of the patient) one of the first steps is to build up and tone up and re-energize the system. The low vitality, induced by an illegitimate drainage of the life forces, must be made up and renewed, and the brain filled with new blood, new stimulation to better and more healthful imagination.

Opposed to the dreams of delicious pleasure and fancies of luxurious joy which a clever young person can catch from even the swing of

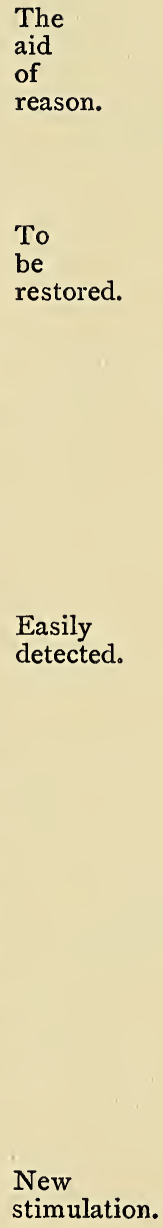


Athletic exercise.

Something to do.

The critical beginning. a poem or the sway of emotional music, and which, when the mind is excited, seem to pour ideas into the head from every side, should be given athletic exercises out of doors, sleep in cool rooms on hard beds and lessons that must be learned and recited without fail, even if the study is made over-difficult for a time and keeps the mind keenly on the strain. Fill a glass with one thing and you cannot fill it with something else at the same time, and when your young patient has all he can cram to avoid censure, in the line of something set for him to do, bodily and mentally, he will have to put off his "long, long thoughts of youth," and his imagination will not have time to play pranks with him.

But, as we said before, the enervated system must have some new and strong foundation to build upon, and especially with very young women. The vital fluid must be constantly enhanced and increased with a clear, clean, healthful stream of pure, rich blood. This, in the critical beginning of her many natural experiences, ranging from this introduction to the mysterious functions of woman to the actual reproduction of herself in another being, is of supreme importance, and probably at no period of life, not even in old age, is found a more imperative need of some outside help with which to aid nature in performing her great mission with fullness, ease and safety.

In fact, youth in both sexes is the physical period of change and doubt. After fifteen the 
system may start with a strong, vigorous bound toward manhood and womanhood or may settle into a puny invalidism for life. Parents know this, but may not think how to remedy or prevent it, but the nurse should supplement the good intentions of the parents with active and persistent measures. Not the least of the many available methods which will come to the quick and able mind of an observant attendant, will be the use of a perfect Malt Extract.

A brain food as well as a nerve food, its excellent effect in pushing the healthier red corpuscles of the blood to the front, as it were, its wonderful exhilaration of all the nervous centers, tending to brace and sustain every bit of gain that is made, gives it a just reputation for efficacy wherever weakness or debility of any organ exists, and without dispute, the porwer of the will and the strength of the character is improved by building up the interior forces into stability.

Some one who had used it in this kind of case made the remark: "In the first place, I banked right up against The Best Tonic," and the idea thus given of the solidity and permanent value of this Extract could but impress the unprejudiced hearer.

It may not be a pleasant duty to inform young people to whom you are called, of things they should already understand and consider, but doubtless it is often necessary, and it should be done plainly, conscientiously and without the least show of false shame. Give the truth, the

A strong, vigorous bound.

A

brain food.

Building

up

the

forces.

Permanent

value.

Often

necessary. 
whole truth and nothing but the truth, in forcible but kindly language, showing personal comprehension and sympathy, but strict firmness in the determination to uproot the evil.

You will probably save a young, valuable life from ruin. 


\section{The Invalio.}





\section{THE INVALID.}

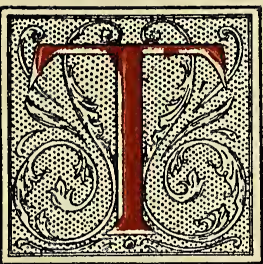

HE nurse is often called upon to minister to others besides those having acute diseases, and when called to the invalid may feel that it is not a very important case. If that is so, the tendency is to give less attention and thought, less earnest care and skillful attendance, than when a disease is of a very serious nature. This, however, is all wrong. To secure a reputation for being efficient, you cannot afford to "go easy" with the invalid. Perhaps you may be convinced that in reality there is nothing truly the matter with the patient, and you feel a fittle impatience and contempt-certain that if you were in his or her condition, you would get up out of bed and go about your business. Now you do not know! You cannot tell! You have no idea what secret mental or heart misery prostrates the form and weakens the will and gives the desire to die rather than to live. No one ever knew the true inner life of another. In most cases, however, you find the cause of invalidism too patent to be ignored and you feel that to set about curing, or if im-

Others

besides.

Heart misery prostrates. 
The

chronic invalid.

Wit

and

kindness. possible to cure, aiding the poor soul, is one of the most useful, beautiful and benevolent of all the phases of your calling. It is odd that all people seem to pity and feel most concerned about a person who is suffering from some unusual attack of disease, while the long, weary, patient suffering of the chronic invalid is passed by with a light "Oh, they are about the same!" Think of the days and nights, for weeks and months, that have been lived in deprivation, comparative solitude, wakefulness, pain, lack of outdoor amusement, lack of healthful exercise which has been suffered and must be suffered by an invalid, which in the long run amounts to a thousand times the anguish felt by a patient with typhoid fever or erysipelas, diphtheria or pneumonia. "Well," you say, "these are acute diseases and people die of them!" So do invalids die, but their death is a thousand deaths instead of a quick one. Lavish yourself, then, on the invalid. Use all your wit and kindness of heart to alleviate every painful or dull hour. Watch their moods. See when they feel like having company and exclude company when they cannot bear it. Be their shield and protection, their sunshine and amusement. Take it for granted that they will often be peevish, irritable, perhaps unreasonable. Disease is not health and does not display the conditions of health. Good temper does not go with a twinge of gout. Take the unpleasant expression or the exacting demand gracefully, and when it is carried beyond reason, simply say 
nothing, but use your own judgment whether the thing shall be done or not. But upon one thing always strictly insist, and that is that the physician's orders shall be obeyed to the letter, the medicine taken and the operations performed with perfect regularity. The responsibility will then not rest upon you, as it would if you yielded a point now and then. To keep the invalid as happy in mind as possible is one of the chief and pleasantest duties of a good nurse. Many patients are unhappy by habit. They have gotten into the habit of thinking themselves forlorn creatures, good to nobody, not even themselves; that they were better dead; that they are a great expense, care and burden, and that people cannot possibly love them. They think they are growing physically repulsive and faded, and dread to have those they love come to see them. They are so sensitive as to their changed appearance, and they brood on a thousand and one real and imaginary evils until they are mentally prostrated and unfit for a cheerful thought. Now a glass that is full of one liquid cannot be filled with another until it is wholly or at least partially emptied of its former contents. So this condition in the invalid must be met with gentle but positive negations, pleasant assurances and reassurances, while the mind is led away from old thoughts into new by an interest outside of the invalid's own body and its various complaints. Always cheerfulness and sunshine, neatness and order, delicately served meals, little surprises in food and occasional di-
Obey

the

physician.

Happy
as
possible.

They

think

they

are.

Cheerfulness

and

sunshine. 
Rest

and

quiet.

And warmth. versions in a tempting drink, take up the mind of one whose sight, taste and hearing are confined to one room or one house, and remembering that the spice of life is variety-have plenty of spice. But there are often cases where utter rest and quiet are more essential than anything else. Very many persons die after being cured of the disease from which they were suffering for the mere want of strength to rise; hence in all cases of sickness the least possible draught should be made on the patient's strength; in an asthmatic spasm, for example, the patient feels as if he would die in the effort to utter a single monosyllable; it is tiresome even to keep the eyes open, hence many will lie with theirs closed for hours; the attention to a question is a weariness. In almost all forms of ordinary sickness and accidental woundings, the very first things to be secured are rest, warmth and quietude. Seriously injure an animal and it at once retires from sight and lies down and rests in a warm place. Thus instinct teaches reason. In many nervous affections and in all fevers, the patient rubbing of sweet oil into the skin with the hand two or three times a day has a wonderfully cooling and soothing effect, while in rheumatism it is remarkably healing and relieves the pain for hours. No anodyne known to the apothecary ever gives natural, restful, refreshing sleep. The essence of all disease is the want of some element to be supplied to the system or to be eliminated from it. Often the dyspepsia, in- 
somnia, lunacy, that we meet with in invalids is caused by nothing more nor less than starvation. They are stomach starved or brain starved, and are victims of too little nutriment. They have, in their invalid state, probably gotten to believe that they cannot eat, cannot digest, and so they do not eat, and not taking anything to take the place of food, they become weak, thin, susceptible to every chill, every fancy, until exhausted nature gives it up and they die. A world of comfort and health is within their reach; they spend hundreds of dollars for things that do them no good, but they do not get enough food into their systems to keep it alive. It is just here that a pure Malt Extract will be of inestimable value in your treatment-an extract of hops and malt-the richest blood making, building and bracing tonic to be had, a beautiful drink to the eye, equally delicious to the taste, which will feed your invalid's stomach and brain, vitalize the whole body, warm and strengthen the system, cure the insomnia, produce a jolly and happy state of mind, re-inspiring a desire for life, a hope for health and an expectation of recovery. An aid to you, as it abets your every effort to reconstruct and upbuild the energies of your patient and offers a perfectly digestible food which added to any light diet which will at first seem to the sick one the only possible food they can swallow, will give the required nutriment while helping to digest whatever else is taken along with it. Boiled rice, pigs' feet or tripe soused and roasted sweet

Starvation.

Too

little

nutriment.

Of

inestimable

value.

A

perfectly digestible food. 
Health giving.

Stop

the tendency.

New trains of ideas. apple are more easily digested than any other food, taking only an hour. Eggs (raw, whipped, boiled or poached), salmon, trout, barley soup, cold slaw and venison steak require an hour and a half more. But any of these may be assisted and accelerated by a good glass of The Best Tonic and the operation will seldom be attended with any distress. If your invalids' stomach is full of good, health-giving food you may count on an easy morning or agreeable afternoon. But do all you can to create pleasant impressions from the outside. The ruts of thought! How they warp and weaken and wreck the intellect sometimes, the forever dwelling on the irremediable past, on sharp pointed memories or remorses. Do you know there is no remedy for a "rut" equal to an emetic? If you have a despondent patient whom you have to watch for fear of suicide, you can stop the tendency by making an emetic which will give them a thorough vomit. The straining and retching will draw the blood from the despondent center of the brain to the stomach and surface, and a fine fit of "sea-sickness" will make a new man or woman of your charge. Many patients are greatly cheered and helped by changes in the room. Even changing the pictures about so that a new one faces the bed or chair has started new trains of ideas and "taken away the pain" for hours. Have all the flowers sent in placed within view but not too near your patient, and if there are ornaments in the room keep putting them in different places, unless she 
is excessively orderly and it irritates to have them moved. If there are photographs of deceased friends about, and the patient tearfully refers to them every day, try to smuggle them out of sight and put something pretty in their places. Let the future, not the past, occupy the mind of the invalid, and magically suffuse the future with rose color. It is a very good thing to give an invalid the dessert half an hour before the regular meal, and let it be in the shape of fruits and berries whose acids enter the blood at once and energize the secretions, or in the shape of nuts and cheese, whose essential oils invigorate digestion, or pure sugar candy, which hastens the more complete solution of the food by its chemical combinations on reaching the stomach. This, of course, when the cause of invalidism lies outside of dyspeptic symptoms. You will find an increase instead of a decrease of appetite when the regular meal is served. Physiological research has fully established the fact that acids promote the separation of the bile from the blood which is then passed from the system, thus preventing fevers and other prevailing diseases of summer and autumn. All fevers are "bilious," that is, the bile is in the blood. Whatever is antagonistic of fever is cooling. Therefore, if your patient yearns for "greens," lettuce, salads, lemonade, buttermilk, never deny the craving. As regards the personal care of the invalid a few ideas may be useful. Whenever any form of bathing is followed by the slightest chill, more harm has been done than
Out

of sight.

Chemical combinations.

Never

deny

the

craving. 
Sound

sleep

invaluable.

Dark

and

well

ventilated.

It

cools

fever.

Beautiful flowers. good. The invalid should take some hot or warming drink at every meal. The Best Tonic produces a permanent heat which extends from the stomach in a radiation of fine animal warmth, from the head to the feet. Never allow your patient to be awakened in the morning. Sometimes after a restless night a few hours of sound sleep can be obtained from seven to ten which will be invaluable. No matter who comes, or what mail arrives, or what the plans are, make them subservient to the invalid's morning sleep. Do not fuss and try to "do up the room," no matter how lightly you can move about, until the person is fully awake of their own accord, for just this moving around may disturb the perfect peace and recuperation of the morning nap. Keep the room dark and well ventilated and keep out of it, if the invalid is slumbering, no matter how late it may be.

Warm water internally and externally, if used with judgment and skill, will alleviate and cure more human maladies than half of all the drugs on the shelves of the apothecary. It cools fever, cures pain, allays nervousness, diverts disease, softens the skin, antagonizes chill, promotes perspiration and soothes the mind.

Let beautiful flowers be everywhere and at all seasons on the mantel of the sick, on the window-sill of the rich, on the tea-table, the breakfast-table, the dinner-table; the very sight of them enlivens, elevates, purifies.

Several forms of gouty pains, the suffering from concretions about the toe and finger joints, and rheumatic agonies are often promptly and 
gratefully relieved, as well as very many other pains, thus: rinse woolen flannels in water as hot as can be borne, wring out, fold up in four or five thicknesses and lay on the suffering spot; as soon as possible cover over with a dry folded flannel larger than the damp one, cover all with a piece of oiled silk to keep in the steam and preserve the heat as long as possible; renew every five or ten minutes, according to the intensity of the pain. There should be two or three sets of flannels, so as to have a hot one on the painful spot all the time, without a moment's intermission.

It is sometimes better, in very cold weather, to air the room periodically, than to have a window constantly open. Great storms of rain and wind prevent one from having a window open at times. A room may be thoroughly aired without danger to the patient, if you cover them over, head and all, with a comforter or blanket for a few moments, and then let the air in from all the windows at once. Keep the blanket over the head a few moments after they are closed, and there will be no chill or cold, while the whole apartment will be as fresh as a rose.

Instead of attempting the vain experiment of trying to purify the air of an apartment with chemical compounds, get rid of it by opening every window and door and let the pure air in.

In your treatment of the invalid, humor the fancy and distract the mind, at the same time having faith yourself in their ease or recovery, and your own courage will impart courage and patience to your charge.

Use

hot.

Air

the

room.

With

pure

air. 

Old ratge. 



\section{OLD AGE.}

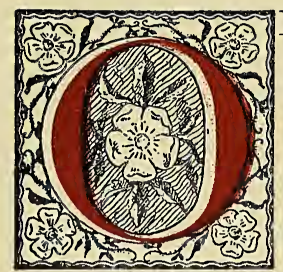

$D$ age is a period of diminished energy. This is its primary, central characteristic and carries with it a diminution of all the powers of middle life. The machinery is wearing out. The old person's activity is growing less, the paces are slower and the pulse less vigorous than when in the prime, the grip is less strong and the manner less forceful There are no longer attempts at great enterprises, nor could they be carried out if undertaken. It does not readily adapt itself to changes of environment. The food is more slowly digested, and less perfectly eliminated. The bones have become brittle and when broken unite but slowly and imperfectly. It is not possible to rally even from slight attacks of sickness without losing each time something of the former strength and elasticity. The teeth are decayed, the cheeks are sunken, the brow is wrinkled, the arteries are hardened, the hair has turned white or fallen out, the sight is dim, the hearing is dull and all the senses have lost their acuteness. Memory of recent events is well-nigh gone and the mental day. faculties are growing weaker every day. 
Without

these

aids.

To

be

envied.

Still

eloquent.

Infinite importance.

This is a picture of extreme old age, as it comes to persons when they have had, perhaps, a life of hard labor, without much enjoyment, monotonous, unstimulated, with no great and constant contact with the outside world or with youthful people, and without those aids to health and those conservations of energy which come from a proper nutriment and rehabiliment of all the faculties.

On the other hand, old age is often seen to be a thing almost to be envied. The greatest minds in the world, the greatest statesmen, to-day, are men long past their middle life-men who are in a green and hearty decline of existence, and who seem as brilliant in mind, as astute in faculty as when they stood, the leaders of art, literature, statecraft or generalship, at forty-five. Such men, full of high ambitions, with a satisfactory environment, nutritious food and drink, contact with the world, stimulation from the young and the pleasant excitements of social intercourse, present the pleasing spectacle of eighty years with the senses still alert, the eye still capable of a flash, the tongue still eloquent and the pen still ready.

How to aid a man or woman to retain their agreeable characteristics, their personal charm and their own health and happiness, is one of the points of infinite importance in the thought of those who love them or have them in charge, during those times when some debility, or some disease, is liable to pull them down.

The period at which old age and its various 
symptoms approaches is determined less by the number of years through which a person has passed than by the constitution and habits of life. Some persons are far advanced in senility at fifty, while others seem hardly to have entered within its borders at eighty. The man who has reached that period of advanced life which borders upon old age in reasonable health, has left many dangers behind him, and is safe from many causes of death which have menaced him along the way. We often wonder to see how long a very old man will hold out, hale and hearty, but we do not realize that the susceptibility to contagious and zymotic diseases which characterized his early life has been exhausted and with it one great source of danger. The period of manhood or womanhood, which is marked by the greatest development of hereditary and general disease, has also passed and from it the system has come forth hardened by the storms and trials of three-score years.

But now is at hand the season when local diseases manifest their greatest comparative activity and virulence. It is the weakest which now gives way, and these are the three vital organs, the lungs, brain, and the heart, in the order named, and later these, the stomach, liver and kidneys.

There remains a considerable proportion, probably from one-third to one-half, of those who reach the age of sixty-five, who, by reason of inherited endurance and favorable circumstances, survive the accidents of life and are car- 
Conserve

the strength.

The object of the Nurse.

And there was light. ried off at last by old age-that gradual fading away of the vital forces which is the only natural death.

To enable old persons to reach this end at last in safety, but not to reach it until it has been postponed to the very latest practical moment; to adapt the environment meanwhile to the changed conditions; to conserve the strength and favor the weaknesses; and to conduct safely through the dangers incident to advancing years and bring them to the close of life by as easy a road as possible, with the greatest amount of comfort and the least amount of suffering: these should be the object of the nurse in charge.

There was a motto on the walls of the Delphian temple ascribed to Chilo, one of the seven wise men of Greece, which ran: "Consider the End."

Probably the motto has always been taken in its narrower meaning as a warning to consider of one's death, but were it not well to consider the end from a little different standpoint? In the sense of making the end of life the best of life, and aiding the aged to that sweet and tranquil period when, the toils and cares of activity all over, "in the evening it shall be light." Why should we assume that because an arm chair is preferred, an easy carriage ordered, a gentle walk chosen or a nap taken surreptitiously after dinner, that now has come the time when that is about all a person needs, and feel that the old lady or gentleman in the household must neces- 
sarily be an invalid, and not possibly interested in the general pursuits of the day? Cheerfulness and fun are the life of our elders, and a good laugh is worth a month's coddling. Practically the old are what we make them! Physically they reflect our opinion of them! If we assume that they are weak, senile and altogether "played out," they will inevitably yield to the younger mind and become about what it has decided they should be; but if we assume that they are no older than ever, and declare that we cannot see any great change in them; if we ask them to join us in our fun and go with us to our social enjoyments, they will not only rise to the occasion but in believing themselves capable of the exertion will find themselves so. The mind probably influences the body in age fully as much as in any other period of life, since it is then perforce more set upon the bodily feelings, and if the mind is kept cheerful, youthful and full of self-confidence, it will carry the body along the way with an ease and a comfort far different from the sad and despondent pilgrimage of one who is acknowledged by the family to be "unable to do anything."

Cold is the greatest enemy of old age. Make it a constant study, during all seasons of the year and at all hours of the day and night, to guard against even an instant's feeling of chilliness; this simple precaution would prevent three-fourths of all the coughs, colds and pneumonias which afflict and destroy the race. There should be a fire kindled in at least one room

They reflect our opinion.

The mind influences the body.

Guard against cold. 
Fever follows cold.

Doubles every nine years.

Avoid undue exposure.

in every house at sunrise and sunset from the first of October, and in the spring up to the first day of June; for every chilly sensation, even if it be but for a second, shows that a cold has been taken; a fever follows every cold, and that is disease.

According to the English Registrar-General, a sudden decline of temperature results in a mortality based upon a given rule in regard to age. In persons under 30 , the effect of cold is not indicated by an increase of mortality; above that age it doubles with every nine years of life. That is, for every one person at the age of $\mathbf{3 0}$ whose death is caused by a certain low temperature, there will be two at 39 , four at 48 , eight at 57 , sixteen at 66 , thirty-two at 75 , and sixty-four at 84 .

Add to the effects of cold those of heat, moisture, winds and sudden changes of temperature, and we have, in a climate like ours, a most formidable array of dangers to old age from atmospheric causes. To*guard against these, the old man must not only suit his food to the climate and season, but he must clothe himself warmly-preferably in woolen garments, as being the poorest conductors of heat-must avoid all undue exposure either to extreme or sudden changes of temperature, and must occupy a comfortable room. His sleeping-rooms should be warm, well-aired and dry. Many a time has the "spare room" proven fatal to gray hairs and decrepit age, resulting in "a cold," pneu- 
monia, death. Of single diseases, pneumonia carries off more aged people than any other.

The portion of the body which most requires protection against cold and wind, is that between the shoulder-blades behind, as it is at this point the lungs are attached to the body, and the blood is easily chilled.

If chilly before bed-time, it is far better to be warmed by exercise than over a roasting fire.

To spend two or three moments, on rising and retiring, in rapid friction of the whole surface of the body with the hand, is a more rational treatment of the skin, and a more health promoting operation, for most persons, than a daily cold water bath.

Rest, quiet and warmth, are the idolatries of the old.

The true idea of rest is recreation; literally, making over again. This is accomplished, not by allowing the machinery of body and brain to come to a stand-still, for inactivity is rust and ruin to all mechanical contrivances, and to all physiological structures, death. Men may be physically old at three-score, but need not be so mentally until beyond eighty or ninety. In a healthy body the mind gets steadily stronger, greater, more magnificent in its accomplishment, for a score or two of years after the first half century. After he was eighty, Palmerston showed no signs of mental weakness, and rode twenty miles a day on horseback for exercise. Disraeli at seventy showed not the slightest sign of "giving up" the leadership of the greatest

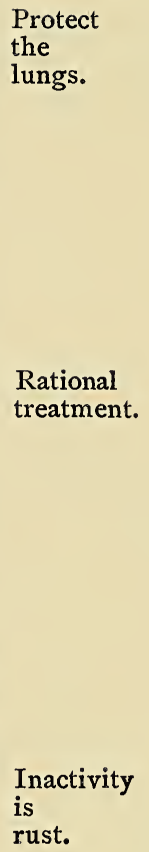


Not

tired of life.

Practice accomplishes the object.

Reason out

the meaning. nation on the earth's surface. Longfellow, and Whittier, and Holmes, and Draper, and Professor Henry, all nearing three-score and ten, were not tired of life yet, nor tired of work, but they felt able to do and dare greater things; and Carlyle, and Thurlow Weed, and Reverdy Johnson, near eighty, were still great captains among men of mind.

A great painter was once asked by a pupil how to mix his colors? "With brains," was the answer. We may know the rules for doing many things, but besides these, there is always needed judgment, skill, and tact; hence, the first trial for doing anything is scarcely ever a perfect success, but practice accomplishes the object in the end.

In the care of the aged, whether the healthful or the invalid aged, the momentary occasion should be the teacher of the nurse. A hint to the wise is sufficient, and many an occurrence will be an object lesson for future use. To reason out the meaning of some of the symptoms which may be observed will not result in ill. For instance, it may be safely said that in many cases where there is some trouble in the throat, with a slight hacking rather than an actual cough during the day only, it is of dyspeptic origin, in connection with improper eating or a disordered liver, being a stomach or liver cough, and to expect to cure it by applications to the throat itself, when the cause of the ailment is nearly two feet away, is irrational and the treatment must fail. 
In this connection it may be well to refer to the need of special attention to the excretory organs on the part of the aged. Regular action of the bowels and frequent evacuation of the bladder should be scrupulously maintained. The term "regular action," however, signifies quite a different thing in one person from what it does in another. While it is generally understood that one movement a day is normal, it is nevertheless true that in some persons three or more movements daily are habitual and needful for comfort, while others can go two, three or more days without discomfort and apparently without injury. But whatever the normal standard for the individual may be once ascertained, it should be maintained with zealous care as a hygienic, I had almost said a religious duty.

Of scarcely less importance is a careful attention to the kidneys and bladder. It should be an inviolable rule with the aged to attend to the calls of nature in this direction at the first indication, whatever else may wait. Enlarged prostate is a common disease in men past 65 , and one which requires careful management.

The best protection against sickness and pestilential maladies is good living, which means an abundant supply of nutritious food well prepared.

Half the time the reason why people past sixty complain of being chilly is because they are hungry! Babies and old people are frequently starved out of life from mistaken notions. An old person needs at least four meals a day, not,

An inviolable rule.

The best. 
Gracious

to

the

stomach.

A

new

atmosphere.

It

should

be.

Sleep recreates. perhaps of as "strong meat" as a day laborer, but of good, wholesome, nutritious, digestible food, washed down by a glass of Pabst Malt Extract, which is like a mellow and lasting heat in the veins, gracious to the stomach, rejuvenating and toning to the nerves, flushing the pale cheek, quickening the ideas, cheering the thought, a blessing that the old can but be thankful for to their latest day. How wonderfully recuperated an old person feels after a wellcooked, handsomely served, tasteful meal, eaten with a joke or a laugh to each course and a glass of Malt Extract "to top off with." A new atmosphere seems to pervade the apartment, lassitude and sad thoughts of an unavoidable past steal away like the Arabs, and in a little while the dear old eyes fold their tents and nod off into dreamland, in a refreshing nap.

Such is the ideal old age, and such it should be the study of the intelligent attendant to bring about.

Of prime importance is sleep. Sleep oils the wheels of life, and lessens the friction of labor. The want of it causes all the machinery of life to run with difficulty, and wear out rapidly. Sleep recreates the nervous system-and sleeplessness breaks down the strongest frame. Especially does old age need abundant sleep, that all the vital forces may be carefully husbanded.

And if your patient is sleepless, restless and uneasy, then pre-eminently come in the soporific qualities of the hops which in this tonic assure calm, restful and perfect slumber. Have plenty 
of light, warm clothing on the bed, keep the air cool and fresh but not cold, advise woolen night gowns for both sexes, have a soft warm blanket to tuck around the bowels and feet of your old ladies, and be assured they will sleep, and fortunately so will you.

To sum up briefly: The food of old age should be simple, nutritious but not too concentrated, not too largely nitrogenous. It should be taken four times a day, in less quantity as a whole than in middie life, and in a soft and friable condition. Stimulants and narcotics summing up. should be avoided, unless required by lifelong habit. Tea and coffee may be allowed in moderation. The calls of nature should be promptly attended to. All excesses should be avoided, and regularity, temperance and moderation observed in all things. Careful protection from cold and atmospheric vicissitudes is required. The mind should be kept active to the last. Avoid worry and fret. Look on the bright side of life. Take plenty of sleep. Give the best of care in health, and of nursing in sickness. Stand between them and all sudden shocks, excitements and fears. Prevent over-exertion. Thus will your patient's life be lengthened, and old age made enjoyable.*

* We are indebted to J. M. French, M. D., of Milford, Mass., for many points in this article. 



\section{Voloman: Iber Tríals.}





\section{WOMAN : HER TRIALS.}

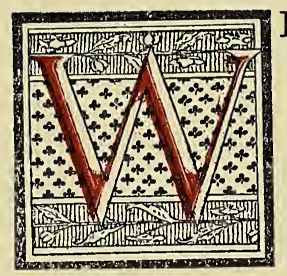

E presume that some who have taken up the kindly office of nursing would very indignantly object to being represented as a cow, or by the emblem of a cow, yet from the very oldest history, even far back of the oldest books of the world, the Sanscrit of the Brahamanas or even of the Vedas, she has been symbolically represented and honored and worshipped as "the good nurse of man, the cow." The Aryan conception merges readily into the womb-man, the feminine half of the dual unity called man, the distinction of being the womb-bearer making one half different from the other; and it is on this caretaker and child-bearer and nurse of the whole race, that woman, in the language of Being, is the Form of the Becoming, the one who, in her bosom, bears the One who, ever born and ever becoming, forever needs the nurse and mother in one, as his other soul, his other body, his other self.

A modification of the meaning occurs in the Egyptian great goddess and nurse of life, Isis, or rather, is-is, Ever-existent, or Being, whom 
Plato calls "the very nurse of the world," both in the sense of sustaining life and giving it, and it is in this profound and deep sense of reverence, of honor, of awe at the gentleness, sympathy, mercy, self-giving and life nourishing principles of the Queen among women, that we find this symbol of the cow at Momemphis, in Egypt, and playing the same important part at Apis, at Heliopolis, and Memphis, while the Phœnicians, Hindus and Greeks in "The Mother of the God of Love," represented the

Beautiful features of benevolence.

Its recognition and worship.

The satire. woman with the beautiful features of benevolence and mercy, often associated, as at Philæ, with the horns and ears of a cow.

It is, then, with a new feeling of interest in the symbolism of past ages, that we find the beautiful ministry of help for pain and aid for suffering had its recognition and worship when literature had not come to be, and only the carved stone of the architect revealed the ancient sentiment; and it can but be with a feeling, not of indignation, but of pride, that we contemplate the fact that the beginning of womanly mercy was with the first known inhabitants of the earliest ages.

It is said that no one is so hard upon a woman as a woman. The satirists of all ages have made their play upon woman's rivalries, jealousies and vanities. The press to-day is rampant with witty, vulgar and clever skits on what they call the "New Woman," as if an original species had been discovered and the blossom of the nineteenth century was something abnormal or wholly unique. But when "illness 
wrings the brow" of the satirist, he does dearly love to have a woman's soft white hand smooth the wrinkles out, and strange to say, such is the confidence woman has in her own sex that often, in the keen trial of becoming a mother, she prefers a female physician; and certainly a female nurse, even if for no other reason than her native modesty, is always properly and eagerly chosen.

But she is chosen for a hundred other reasons, and best of all, because she is a woman herself. She has endured the trials of a woman and is more apt to feel the pangs of her patient in keen response and delicate comprehension. She has, to put it slangily, "been there," and she helps her patient, in spite of a thousand ills, to "get there all the same," that is, get back to the perfection of health, beauty and comfort.

The ills of woman are so many, and so many of them depend upon "the nerves," that from neuralgia to hysteria, from uterine diseases to mental derangement, we can almost invariably trace them back to the delicate, tiny, almost invisible thing we call a "nerve." Some composer once got up a street song, "Oh, Hasn't $\mathrm{He}$ Got the Nerve," and a woman, hearing it, exclaimed, "That fellow wouldn't know his aunt from his uncle!" for she fancied "Oh, Hasn't She Got the Nerve," would have been far more appropriate. And we can but echo her idea in another sense, for it certainly does take nerve to voluntarily assume the expectation of motherhood, as many women do, not once, but several

Such

is

the

confidence.

Delicate

comprehension. 
A

curious custom.

A

soft snap.

In

Biscay. times, knowing all that must attend the whole process, and its almost uncertain and sometimes most dangerous outcome. As an illustration of the dual unity of man and woman, as recognized in the remotest ages in other ways than by religious symbolisms, we would note a very curious and otherwise inexplicable custom called the "Couvade," which extends from China to the Mississippi Valley; it demands "that, when a child is born, the father must take to his bed, while the mother attends to all the duties of the household." Marco Polo found the custom among the Chinese in the thirteenth century.

The widow tells Hudibras-

"Chineses thus are said

To lie-in in their ladies' stead."

The practice remarked by Marco Polo continues to this day among the hill-tribes of China.

"The father of a new-born child, as soon as the mother has become strong enough to leave her couch, gets into bed himself, and there receives the congratulations of his acquaintances." (Max Müller's "Chips From a German Workshop," vol. ii., p. 272.) Strabo (vol. iii., pp. 4, 17) mentions that, among the Iberians of the North of Spain, the women, after the birth of a child, tend their husbands, putting them to bed instead of going themselves. The same custom existed among the Basques only a few years ago. "In Biscay," says M. F. Michel, "the women rise immediately after childbirth and attend to the duties of the household, while the husband goes to bed, taking the baby with him, and thus re- 
ceives the neighbors' compliments." The same custom was found in France, and is said to exist to this day in some cantons of Béarn.

Now, if the husband could only be induced to assume the pains of travail and labor preliminary to these interesting after-scenes, woman's trials would be reduced to a remarkable degree.

Some North American Indian women seem to have learned how to have a child with the least possible pain and trouble, and it is possible their white sisters might take a hint from them. Their position in the act of parturition is that of squatting, and they take hold strongly of two large, strong corn-cobs, one of which they grasp in either hand, thus steadying themselves and giving themselves the aid of a "hold-fast." At the first pang they swallow a couple of gallons of as warm water as they can possibly take, fairly filling themselves to the brim, and the relaxation of the muscles causes the child to drop out, sometimes so easily as to cause the mother but a single groan. It was remarked by a physician who heard the above, that among white women injections of hot water to supplement the interior heat would doubtless be of great value in extreme rigidity.

But most of the time women are enduring the opposite trial from the bearing of children; they are menstruating thirteen or fourteen times a year, and often this period takes seven days of the thirty or thirty-one in actual flow, with at least from two to five of restless interior preparation for the great event. For with many women

Hot water of

100 days each year. 
At
least
ten
years.

Invigorate

the

system. the monthly period is a great event, dreaded, hated, endured, but as you well know, never "embraced," excepting when, like Hamlet, "the dread of something after" its non-appearance, "makes us rather bear the ills we have than fly to others that we know not of!"

Truly one might say that when one considers that during a third, night and day, of the thirtyone years, from fourteen to forty-five-a good round ten years of a woman's life, she must be in a state of annoyance, if nothing more-her nerves upset, her head aching, her whole body often racked with cramps, coldness, depression, extra and dragging garments, confinement to the bed or sofa, giving up engagements or necessary work, ranging in her trial from too much to too little, too often or not often enough, paling her cheeks, dimming her eyes, taking the elasticity from her step, the enjoyment from all her pleasures, she might again fitly exclaim with the melancholy Dane:

"There's the respect

That makes calamity of so long life!"

Very many women, as well as men, look forward longingly to the time when they shall be able to "retire from business," even although there is a popular superstition that all womanly charm, fire, physical enjoyment and personal beauty fade out with the stopping of that peculiar function; but you, as a nurse, are well aware that this superstition is fallacious where proper care has been taken to keep the system constantly invigorated during the whole of woman life with all its varied vicissitudes. 
The fact is, we know not the time when Pabst Malt Extract, The Best Tonic, is not needed by women, from six months before puberty until old age creeps over them, for certainly there was never anything better invented for soothing, warming, nourishing, sustaining, easing and helping during the menstrual periods and the preparation for them; during the bearing of a child and preparing to give it proper milk; during the recovery from child-bearing and during child-suckling, when all the energies are drained; or at any other time when nervous strain, physical labor, mental anxiety, shock, sorrow or pain assail and reduce the body to the need of outside assistance!

Many times when you are called to attend the sick-bed of a woman you find that the root of her whole trouble is, that she is tired. She is tired, weary, worn out with something or other, which has brought on uterine difficulty, or low fever, or some nervous symptoms which are named this or that.

We talk about the health-giving influences of the wash-tub, and the sanitary value of wives and daughters having to cook and brew, and bake and sew, and scrub every day, as the sure means of having healthy, vigorous children; but carefully ascertained results show that of one thousand infants of the rich and as many of the indigent, fifty-seven of the former died before five years; of the latter three hundred and forty-five.

Some women treat themselves and many women are treated by their husbands as if they

Saving and helping.

Tired

out.

A theory. 
had the strength of a horse. If they are too wealthy to be obliged to go to the wash-tub they go "into society," and plunge into the suds of life, hot and cold, driving and pushing from noon to midnight, either at home or in the houses of others! Charity, clubs, societies, church, mission-work, dinners, dances, theaters, all crammed

Finally

you

find

them.

Just

in

The result.

Try

it. into a week, and finally you find them moaning on their laced and beribboned pillows, "I can't imagine what makes me feel so tired! I can hardly raise my hand to my head."

A lady in Washington made 3,800 calls in one season, besides her other engagements. This is a fact. Many calls were "diplomatic," carefully studied, done for a purpose, full of brain and nerve tension. She had a nurse six months to pay for it, and just recuperated in time to begin another season. Such lives as these are by no means few.

If the exhaustion of the vitality is not from one cause, it will be from another, and hysteria, fainting, suicidal mania, intense depression, or an attack of acute disease is the result.

A recent scientific journal gives the following cure for one of the greatest trials of womannervous headache. Have your patient walk backwards for ten minutes, slowly, carefully resting the feet first on the ball and then on the heel. If it can be done in the open air all the better, if not don a cloak and hat, if in winter weather, open all the windows and walk about the room. It is said to be an almost certain and speedy cure. 
In long fainting spells, lethargy or loss of respiration from any cause, Dr. Berthold Beer recommends that the mucous membrane of the lips of the mouth be rubbed slowly with a piece of ice, the rhythm of the motion corresponding as nearly as possible to that of normal respiration. He claims that the inevitable result of the treatment is the return of respiration, at first in a very pronounced form, but becoming, on the continued application of the ice, very regular, quiet and deep. Ice used in this way has also a general sedative effect, and its quieting action has been successfully turned to account in the treatment of cerebral troubles. Dr. Foges has obtained equally favorable results with this treatment in cases of suffocation. This method may be employed for several hours at a time, and is said to be harmless for the patient and easy for the nurse.

In all the diseases or trials peculiar to women, warmth, heat, is most essential. The body craves to be petted and caressed with a sense of cozy sunshine, and sometimes absolute rest, accompanied by plenty of heat will stave off an approaching illness and cure "miraculously." A warm "stew," getting into bed with covering well tucked in, hot bricks to feet, and drinking abundantly of hot Best Tonic until there is a dripping perspiration, to be kept up an hour or two or more until the system is relieved, and

Rub slowly with ice.

Also in suffocation.

Rest and sunshine.

Hot

Best

Tonic. then to cool off very gradually in the course of another hour, is derisively styled an "old woman's remedy;" but for all that it will break up 
Without danger.

Win

you

the

gratitude. any cold taken within thirty-six hours; it will promptly relieve many of the most painful forms of sudden disease, with the advantage of being without danger; gives no shock to the system, nor wastes its strength.

Do not forget the "warm stew" in the stomach, made of hot Best Tonic, which will delightfully fill the patient with peace and ease "beyond the dreams" of one unaccustomed to using it, and there is hardly any trouble that will not yield to its magic spell. In fact, remember these following six things adhered to with firmness will win you the gratitude of any woman you treat:

1. Loose bowels.

2. Abundant warmth.

3. Sound sleep.

4. Plenty of good things to eat.

5. Purę air.

6. Pabst Malt Extract. 
Illsan: Ilbis Troubles. 



\section{MAN : HIS TROUBLES.}

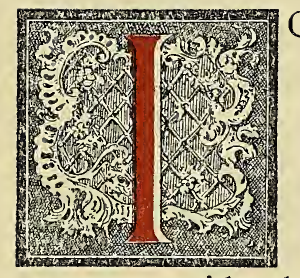

CHALLENGE any man to produce in the joints and pivots of the most complicated or the most flexible machine that was ever contrived, a construction more artificial or more evidently artificial than that which is seen in the vertebræ of the human neck. Two things were to be done: the head was to have the power of bending forward and backward, as in the acts of nodding, stooping, looking upward or downward and at the same time of turning itself on the body to a certain extent, the quadrant, we will say, or rather perhaps, a hundred and twenty degrees of a circle. For these two purposes two distinct contrivances are employed: first, the head rests immediately upon the uppermost part of the vertebræ and is united to it by a hinge joint, upon which joint the head plays freely forward and backward, as far either way as is necessary, or as the ligaments allow; which was the first thing required. But then the rotary motion is unprovided for; therefore, secondly, to make the head capable of this, a further mechanism is introduced-not between 
Tenon

and

mortise.

Motions perfect.

Natural theology. the head and the uppermost bone of the neck, where the hinge is, but between that bone and the bone next underneath it. It is a mechanism resembling a tenon and mortise. The second or uppermost bone but one has what anatomists call a process, namely, a projection somewhat similar in size and shape to a tooth, which tooth, entering a corresponding hole or socket in the bone above it, forms a pivot or axle upon which that upper bone, together with the head which it supports, turns freely in a circle and as far in the circle as the attached muscles permit the head to turn. Thus are both motions perfect without interfering with each other! When we nod the head we use the hinge joint, which lies between the head and the first bone of the neck. When we turn the head round we use the tenon and mortise, which runs between the first bone of the neck and the second."

Thus writes the venerable and beloved William Paley, Archdeacon of Carlisle, in his beautiful work "Natural Theology," in which, by this and similar exquisite illustrations, he proves the Intelligent Design of the Creator in his contrivance of Nature and of Man, while at the same time with simple eloquence he draws to the Great Designer the willing adoration of the heart.

Man may not sufficiently realize, in the hurry and worry of daily life, the overshadowing love and care which everywhere surrounds him, from the cradle to the grave, nor think, until some function of his system is deranged and places 
him involuntarily upon a sick bed, how deeply he is indebted to the forethought, the wonderful invention of God, in first making the human body the piece of perfect mechanism it is, and then through long years of untiring motion and effort, keeping it in correct running order, for the uses of the spirit which is contained therein! But the sudden injury, the contagious disease, the hard cold, leading to pneumonia, the fever, the prostration of the nerves, the loss of a limb, the darkening of the eyes, the rheumatism of the heart, the pain in the kidneys, the inaction of the liver: these and other troubles which cause him to lie down to suffer and perchance to think, give him a personal insight of the amazing average of his existence in ease and peace, full of active and happy usefulness and brimming with pleasure.

In contrast with the carefulness and forethought displayed in the mechanism of the body itself, is the ignorance and recklessness with which most persons use it. A man who would no more put his gold watch in a basin of water than he would burn up a hundred-dollar bill, will do equally absurd and dangerous things with his body, as if it were made of iron or even cast steel and nothing could hurt it. Dr. Robert Macnish, of literary fame, acknowledged that at four different times, in spite of all he knew, he deliberately did things that endangered his life. At fifteen he induced a dangerous brain fever by injudicious habits of study; at nineteen by excessive efforts in wrestling and jumping,

Perfect mechanism.

Suffer and think.

Carefulness versus recklessness.

Injudicious habits. 
Dyspepsia appears.

Nervous debility.

Pleasures pale. violent peritonitis was the result. After that he had an attack of inflammation of the lungs as a result of dissection at an open window in midwinter for several hours, and at last a dreadful fever from dancing all night and going out into the winter air without any cloak or overcoat, getting thoroughly chilled before reaching home. Many, absorbed in business, go to their "meals irregularly or skip a lunch or dinner when already hungry, and pretty soon dyspepsia puts in its appearance. Others carry their affairs around with them, as Franklin did his loaf of bread, and never let them go-so at night they do not sleep, have no real rest and pretty soon get run down and sick with a low fever or nervous debility.

Nervous debility ends in nervous exhaustion, arising from an insufficient supply of nutriment to the nervous system, because the food which the man eats is not fully digested. Some of the earliest symptoms are named, so that they may be the earlier attended to: accustomed work grows irksome; the closing hours of the day are attended with greater fatigue; the usual sources of pleasure begin to fail; trivial annoyances become more annoying; domestic matters become more irritating; fault-finding is more pronounced, more frequent, and more extended; pleasures pale, the sun no longer shines, the birds no longer sing, and all nature is clothed in sackcloth and gloom-in the imagination.

Like everything else, not a trouble visits a human being without its adequate cause, and often 
the prostration of the powers could have been avoided had moderation been observed in the passions, the appetites, the brain stimulants or the bodily exercise of your patient.

Disease, with its attendant nervous exhaustion, is often attributed to over brain work; but it ought to be known that thought, which is legitimate brain work, strengthens the mind as body work strengthens the body; bodily power, capability, is limited, the power of thought is without limit or boundary. Nervous exhaustion is the result of brain worry, that is, mental or moral causes, or of brain starvation. The nervous system must be fed; must be supplied with nutriment derived from the perfect digestion of sustaining food; dyspeptics cannot furnish that, and the nerves are thrown into the irritability of starvation; they complain for the want of something to eat; hence a starving brain and a starving man have symptoms in common with one suffering from nervous exhaustion, commencing with exaltation, like that from liquor; then comes exhaustion and failure.

How often we hear the expressions: "He works upon his nerve," or "He lives on his nerve," and how many exclaim, "Oh, I just live on excitement!" Every kind of excitement, as such, is eagerly desired and ardently followed, whether it be in society, in stimulants, in speculation, in athletics, in sport, in the passions. As a result the fine mechanism of the body and brain become upset, deranged, disordered, clogged, stopped. The blood becomes impure

Observe moderation.

Mind

and matter.

Nerves need feeding.

Nervous excitement. 
Live healthfully.

Causes

of

ill

health.

Busy

heart.

or thin and watery, the greater organs refuse to perform their natural functions, and the first epidemic, like the Grippe, or the natural outcome of the particular phase of man's condition will call the physician and the trained nurse to his relief.

Yet man is an adaptable animal, intended to live, thrive and flourish in all latitudes and in all climes and to be surrounded with great variety of changing circumstances; and he can live healthfully and long under the equator or at the poles, if he will only conduct himself in wise accordance with his surroundings.

This is not, however, always possible. Men have ill health come upon them from business reverses, loss of their beloved, personal mortification, sharp-pointed memories, domestic perplexities, agonizing relations. The more honorable the man the more sensitive and acute his feelings and the more the effect upon his body. Some men work themselves to death! They keep hands, head, heart in continual action, for a hobby, for their families, for money, for fame! And not counting the steps of the feet, the work of the hands, and the motions of the body, but only the motions of the little, busy, busy, beating heart, which thumps three thousand million times without a stop during our pilgrimage of threescore years and ten, it propels to the utmost extremity of toe and finger half a million tons of blood, each stroke representing a force of thirteen pounds!

It behooves all, then, to be sure that the food 
and drink which we supply to such an engine shall be of the purest, freshest and best which can be found. In taking care of a man in his troubles, the nurse will have to take into consideration at least a half dozen of the possible reasons which have caused him to need such service, and the kindly labor of restoring the system to its normal balance will be greatly guided by such intuitive knowledge as will supplement the supplied information.

The lungs of an ordinary man contain over half a thousand millions of air cells; if these were cut open and spread on a wall they would cover a space of six feet each way, representing the surface which is exposed to the air at each breath. No wonder a man has "trouble" with his lungs if the air is very cold and the body not sufficiently protected by flannels, for his whole body gets chilled and pretty soon pneumonia is the result.

Again, men suffer intolerable agony from what is called a "simple" disease, namely, the piles, and at last you are called to assist, since he can stand them no longer-whereas, if the proper diet had been strictly observed, no cheese, no toasted bread, everything of a loosening character used and everything of a constipating character abandoned, they would hardly have come to such a point. Inject Extract of Hamamelis, the witch hazel, half and half with cold water, six times a day, and bathe over and again with it. All the salves in the world will not compare with this simple treatment. In ex-

Pure

food.

The

lungs.

Piles. 
Witch

Hazel.

Something better.

Best Tonic.

Mental anxiety. treme cases place pounded ice over the parts after the injection. Almost all salves heat and burn, petroleum in any form is acrid, but witch hazel is cooling and healing. Rheumatic troubles bring a man to his bed, and you at once see the necessity to ease him by any possible method. Hot compresses, constantly re-applied, are of great value. Add olive oil to everything he eats, if you can. You don't hear of Italians having much rheumatism. Wine and oil were the great "cure-alls" of the ancients of all nations: the wine to elevate, sustain, and strengthen; the oil to feed, lubricate, nourish, invigorate and warm. Fortunately we have now something in every way better than wine, without the possibility of temptation to continue to "strong drink," as wine will sometimes tempt, but which contains in itself elevation, sustaining power, strength, food nourishment, invigoration and warmth. Those qualities are just what it is preeminent in; those qualities won it the 100 points of perfection from the best judges in the world; those points are part of its virtues, which can be used for the advancement of your patient toward health at a quick pace! We mean Pabst Malt Extract, The Best Tonic, the combination of hops and malt par excellence; the unalloyed and unadulterated acme of purity.

There is hardly a trouble to which man is subject, and to which you will have to bring your best skill and attention, that does not arise from either mental anxiety or physical overstrain. You do not have many lazy, lackadai- 
sical, easy-going, moderate, contented-minded patients to treat; now, do you? It is he who works, who thinks, who don't take good care of his body, who overdraws the forces of his body in excess, or in overeating or overdrinking, or being up late nights in the cold, or traveling too long and drinking too many kinds of water, or diving into places where there is disease: these active ones, full of purpose, full of aims and ends need you at times, and you cannot but give them a heartfelt sympathy, for they do not come often, and when they do they seem as helpless as children. Women know how to be sick, but not many men do! Gracious Providence that they do not-for they cannot afford it!

Perhaps there is no more grateful or soothing thing to a sick man than "being rubbed." It imparts a soothing sense of drowsiness and ease, and in great pain will sometimes seem for a time to remove it. To rub with oil is a most soothing thing, and to gently bathe with alcohol heated, is of the finest stimulation. It freshens the whole body. Don't be careless and let any part be exposed while you rub another part! Kneading the liver is well worth understanding also. It aids in removing several bodily discomforts. It is done by using the ball of the right hand and rubbing downwards, beginning at the right hipbone and the edge of the ribs and coming round to the center of the body at the navel. 'As the liver' is a large gland between these points, a portion of it resting on the stomach, it is stimulated by pressure, which, in a 
Relieving constipation. sense, acts upon it as the same pressure would act on a sponge filled with water, the effect being to force the bile in the liver onward to the point where it is discharged into the alimentary canal, just under the stomach. In this way the liver is sometimes made to work. This is also a good method of causing gases in the stomach and the acute pains that accompany them to pass downwards; it also causes the muscles of the stomach and its appendages to have a more healthful motion, antagonizing a constipated condition of the system. On finishing the careful and thorough rubbing, which will have so good an effect, give your patient a wineglass of The Best Tonic, and take one yourself, if he is willing to provide it, for you will certainly deserve it!

It is a valuable rule of universal application that if in doing anything, discomfort follows, cease at once, as persistence always makes a cure more difficult and dangerous. One of the most painful and prostrating troubles of men is Gravel. the deposition of gravel or stone in the gall or urinary bladder or passages. This you can arrest and the stones can be softened and melted away by having your patient drink positively nothing but milk, and using no bread or water, but rice instead. Bread and water both contain lime, which you wish to avoid. He may eat rice, milk, meats, fruits and berries.

Supposing you suspect that your patient has taken something poisonous into his system, or has been dosing with things he should not use 
in his case, the safest and most instantaneous emetic known is a teaspoonful each of salt and ground mustard seed stirred quickly in half a glass of water and swallowed promptly. Almost as instantly is any poison taken into the stomach vomited up.

If your patient is in a condition where intolerable thirst abounds, but when he cannot be safely allowed to take water, or he cannot well swallow, or for any other reason, it has been known for a hundred years that if you put on him a garment saturated with salt water (Ditman's sea-salt will do if you cannot get sea-water), it quenches the thirst, because the warmth of the skin sets up a distilling process and the vapor of the water makes its way into the circulation, the particles of salt being too large to enter and too heavy to rise. Put the garment on hot and cover your patient warmly and he will not take cold.

To keep your patient cheerful and hopeful is a paramount duty. If a man is despondent he will not rally so quickly from disease. For one thing, tell him that the statistics of disease show an average that is well illustrated by the following record of a dispensary which kept account of all the cases presented to it for six years. There were admitted 6,420 . There were cured 5,476. There died 243. This is about the average of the recovery from disease in general. His chances are very great, then, for recovery. And another thing: it has often been observed that after a "good spell of sickness" the system

Safest

emotic.

Quenches

thirst.

Dispensary record. 
seems to be rested, strengthened, cleaned out of all its spleens and humors, and a man will declare with a self-congratulatory smile: "It was a hard pull while I was sick, but now I never felt so well in my life!" 
\$urgerp.

$+$ 



\section{SURGERY.}

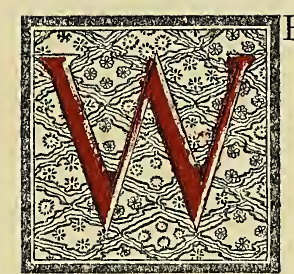

E think a most appropriate motto for a nurse would be, Res est sacra miser (a suffering person is a sacred thing). The ministration of suffering is often the benediction of love, and makes the person so visited an object of reverence and tenderness. In India the hunchback, the cripple, the blind, the deformed are ever treated with profound respect. In some countries the idiot is called "God's Fool," and is the object of the solicitous care of all who meet him, whether strangers or otherwise. Many believe that to touch a hunchback or an idiot brings good luck, since he is under the especial protection of the Almighty, and we all know what the Christ said of the children: "Take heed that ye despise not one of these little ones; for I say unto you, that in heaven their angels do always behold the face of my Father which is in heaven." Perhaps there is no sight which appeals to the sympathy of an attendant on the sick more pitiful, more thought-compelling than a human body crushed and broken, mangled and marred by some untoward acci-

Nurse's motto.

Good luck.

Crushed and broken. 
Personal injury.

Diseased body. dent, or the exposure of some terrible sore or wound which requires the beneficent gash of the surgeon's knife. Human instinct is strong for perfection. Blemish the rose with a single faded leaf, and the involuntary impulse is to pluck it off! Stain the purity of the statue with a single dark vein in the marble, and there is a sense of dissatisfaction. Beauty, grace, charm in the human form divine call forth our warmest enthusiasm, and it is with a sense of personal injury, a painful feeling of lost harmony and discord, that we notice even so slight a defect as a squinting eye. It is not surprising, therefore, that the physician and his faithful adherent, the nurse, keep for surgical cases a profound sense of importance. Eagerly they lend their best service to the restoring, as far as may be possible, the broken limb or displaced bone to its natural position, or to freeing the diseased body from those terrible fungus growths, tumors, or marring sores which reduce the patient to death's door, or utterly take away the attractive quality of the personality. Men, women, and alas! children, are constantly under the able and untiring care of those who, in hospital wards or private asylums or homes, have met with some terrible disease or accident which has prostrated the powers.

We are indebted to Dr. W. W. Keen, of the Jefferson Medical College, for the following blank intended for those who have occasion to do or attend upon cases of surgery upon women in private houses. The carefully arranged list 
of things should be provided in all cases where a severe or very important surgical operation is to be performed, and from this list the intelligent nurse can arrange other and less expensive lists of necessary articles for the needs of less exacting operations-the following including all that would probably be of use in the most "life and death" exposition of surgical skill.

\section{I.-THE PATIENT.}

1. The day before the operation shave the parts; scrub well over a wide area with soap and water; then with ether; then with a sublimate solution, 1 in 1,000 ; then apply a sublimate gauze dressing and bandage and let it remain in place until the operation.

2. See that the bowels are opened by a gentle purge given the previous evening, and if need be by a morning enema.

3. Wash out the vagina and rectum.

4. For breakfast a cup of clear soup (no bread or other solid food) and none later.

5. Have the patient in bed (in an adjoining room, if possible) a half hour before the operation, with night-dress, chemise, drawers and stockings only.

\section{II.-THE ROOM AND BED.}

1. Take up the carpet, remove curtains, draperies and all furniture except a bureau, washstand, table and two cane-seat or wooden chairs. Clean the room. Clean the wall and 
ceiling with a brush and broom covered with a towel; then wash the floor, wood-work of walls and furniture with carbolic solution, 1 in 40 ; have clean carpet strips ready to lay on the floor after the operation.

2. A firm four-legged table, with three old blankets and a pillow in front of a window (north light preferred).

3. Remove the window curtains and screen the lower sash by paper or towels.

4. Four small tables for instruments, dressings, etc.

5. Protect the floor.

6. Two blankets on the bed instead of sheets.

7. Protect the bed by a rubber cloth and a draw sheet.

8. Ten hot water bottles well corked.

9. Hoops to support the bed-clothes.

10. Waste-water bucket.

11. Five china basins and one tin basin.

12. Three sheets and fifteen towels wrung out of sublimate solution, 1 in 1,000 , the night before the operation, and rough dried.

13. Two dozen large safety pins.

14. Tumbler, tablespoon and teaspoon.

15. Nail brush.

16. Two pitchers of cooled boiled water.

17. Plenty of hot water.

18. A sheet of stout wrapping paper for the Allis inhaler.

19. 1 1-2 yards flannel for a binder.

20. Fresh clear soup and milk.

21. Olive oil, two ounces. 
22. A pint of vinegar, to cleanse the hands after operation.

\section{III.-DRESSINGS, ETC.}

1. One can of sublimate gauze.

2. One roll of wood-wool dressing.

3. A piece of rubber dam, ten inches.

4. Four bandages three inches wide.

5. Two ounces of borated cotton.

6. Quarter pound of Globe antiseptic wool.

7. Bed pan and urinal.

8. Catheter.

9. Thermometer and temperature chart.

10. Hypodermic syringe.

11. A bent glass feeding tube.

\section{IV.-MEDICINES, ETC.}

1. Carbolic acid (No. 1) fl. oz. vzs. in a halfgallon bottle of distilled water.

2. Carbolic acid (No. 1) fl. oz. vj.

3. Two one-half pound cans of squibbs ether.

4. Chloroform fl. oz. iv.

5. Liq. morph. sulph. fl. oz. j.

6. Four suppositories, 1 grain opium each.

7. Spirits ammonia aromatic fl. oz. j.

8. Alcohol oj.

9. Ten-grain powders of sulfonal, No. iv.

10. Brandy fl. oz. iv.

11. Lime water, fl. oz. iv.

12. Sublimate tablets for 1 : 1,000 solution, No. 22. 
For other operations Alexander Mills, M. D., of Edinburg, in The London "Hospital" menHelps. tions many conveniences and helps in all sorts of surgical operations:

Hair pillow, feathers being too soft.

Mackintosh pillow slip.

Broad belt to pass over patient's chest and another over the knees.

Clove-hitch garter, consisting of a knitted wool strap two inches broad and seven or eight

And feet long, to prevent struggling. To the other conveniences. dressing conveniences he adds: Two kidneyshaped basins; two bleeding cups; a dozen sponges; bottle of turpentine; a quantity of carbonate of soda; jar containing drainage tubes; jars containing ligatures of cat-gut, whale-gut, kangaroo tendon, silk, horse-hair, silver wire; lead buttons for sutures; elastic webbing; various syringes, and a box of saw-dust or large tray under operating table.

But the use of all or any of these will depend upon the case at hand, and be ordered by the surgeon in attendance. However, it is well to know that all these articles are used and come into

At times.

Don't delay. play and at times are indispensable; while the necessity of absolute thoroughness in the cleanliness of the room and all its adjuncts is palpable.

It is well known that many patients do not come to the period or necessity for operations until they have been reduced by a disease to great weakness, or else they do not consult a physician in time, so that when they should be 
operated upon the system is in no condition to endure the shock, and for weeks at a time they are obliged to suffer and wait until they can get strong enough to be freed from their trouble. Often from delicacy women will go so long before they are examined that their lives are in the balance, and they are given a choice of an operation with possible death, or death itself from the condition in which the surgeon finds them.

In all cases where a surgical operation is to be performed, the stronger the general system of the patient, the cleaner and fresher and richer and fuller his or her blood, the better are the chances of life and recovery. There is no time when the constitution of a person is more tried than in resisting the nervous shock of a surgical operation, and if an accident has been the cause of fracture, or they have long had troubles arising from an impure condition of the blood, the vital necessity for a rehabilitation before they have to endure the knife is plainly apparent. It is, then, essential that when there is time for any preparation at all, that the patient should be nourished to the best degree and the nerves toned to the calmest and most healthful state, while the blood should be enriched and the amount of fat produced which will help the system after the operation has been successfully performed, but from which they must have sufficient vitality to recover. At this point, as in other cases of debility or of lost forces, or in all cases where nutriment that shall brace and 
Brace, build, conserve.

Daily reconstituents.

Remarkable recuperation. build and conserve strength is needed, Pabst Malt Extract is nothing less than a God-send to the expectant or the gratified sufferer. In the one case it will aid the food to enhance the very life-blood, so that the loss of some will not deleteriously drain the body of its power to live; while in the other case, where, as in an accident, the sudden loss of blood has occurred, it immediately begins to rapidly re-supply the element of existence and will materially aid, quickly and surely, in the pouring new life into the veins.

In all suppuration, where there is ever a constant drainage of the body, daily reconstituents must be given the system, or the strength will slowly but surely ebb away; and it is with pleasure that we can testify of the enthusiasm of noted physicians on the excellent results obtained where it has been used for the sustaining of such persons.

One of the most remarkable recuperations from hemorrhage that has come under the observation of the writer was personally attended, and was in this wise: The patient began to bleed from the vagina in quick sharp pulses and spurts, showing that the loss was of arterial blood. Before a physician could be summoned she was reduced to fainting, and it was declared that five minutes more would have literally drained her system so that she would have died. It was ascertained that the flow was from a cancer, located near but not on the womb, and for three weeks her life hung in the scale. She was at once put on a diet of light food, the prin- 
cipal portion of her nutriment being The Best Tonic, to which was added a good extract of beef. For weeks she hardly took one-quarter proportion of any other food, but gained after the first three weeks, until at the end of three months she was built up to a state of good vitality, so that she traveled $\mathbf{1 , 0 0 0}$ miles to a new home and lived over two years, when she succumbed to repeated hemorrhages and the ravages of her dread disease.

In this case, the life was poured back into the body of a large and not too vigorous woman of fifty-eight, suffering with cancer, who had lost almost all of the blood in her body within a few moments, so that she had at least one year of comparative ease and happiness before the inevitable end. This lady had been herself a professional nurse, and in all such cases had prescribed or suggested the use of the Malt Extract with such fine results that she confidently relied upon it in her own critical case.

As regards the care of children, especially in surgical cases, all the kindness of heart, the sweetness of temper and the patience of a nurse will probably be called in play. Some have advocated that some nurses should make a specialty of children and care for them alone, for they certainly require different handling from the adult. They are not supposed to be reasonable or to understand the necessity for the treatment they receive, and if they rebel, it is little to be wondered at.

All attempts at handling the child in cases

To

good

vitality.

Used

Malt

Extract.

Care

with

children. 
$\mathrm{Be}$

firm.

Entirely dependent.

Cleverness

and ability. of accidental injury are apt only to increase the child's terror and pain, and make the task of dealing with the little one almost hopeless, especially if the mother adds unreasonableness to the child's fright.

When this patient gets into the ward, if he is sent to the hospital, he is entirely dependent upon you. He can give no reliable help in detailing his symptoms, probably refuses all food or medicine offered, and cannot be trusted at all with his own feeding or dosing. He has to be coerced into quietude against his natural bent, and he is sometimes so full of tricks that he can master the untrained nurse. Then, in the case of an operation, there are so many minute details to be attended to and so much scope for the exercise of individual ingenuity that you can show your acuteness and skill in no more satisfactory way than in the successful treatment of his puzzling case. In fine, in all surgical operations, whether of one kind or another, on women, men, or children, the reputation you will gain will come as much from the cleverness and ability of your own individuality as from the teaching you may have obtained, and if you are equal to the emergencies that will arise, and display tact, foresight, calmness and courage, you will be sought by all the physicians of your locality, and you will be the stand-by and comfort of unnumbered families. 


\section{I Ittle Chapter of Motes}

On the

Ulse of SiDalt Extracts in Dísease. 



\section{A LITTLE CHAPTER OF NOTES}

ON the USE of Malt Extracts in Disease.

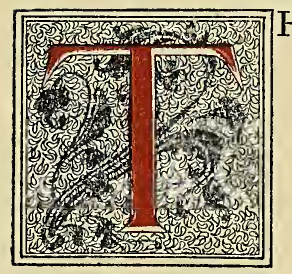

HE varieties of diseases, the care of which will come to the experience of the competent nurse, remind one of the incident recorded by St. Mark in the New Testament. Christ met a man with an "unclean spirit," who had his dwelling among the tombs, and no man Unclean spirit. could bind him, no, not with chains. And always, night and day, he was in the mountains and in the tombs, crying and cutting himself with stones. But when he saw Jesus afar off he ran and worshipped him, and cried with a loud voice, "What have I to do with thee, Jesus, thou Son of the Most High God? I adjure thee by God, that thou torment me not!" For he had said to the man, "Come out of the man, thou unclean spirit!" And Christ asked him, "What is thy name?" And he answered and said, "My name is Legion; for we are many!" Yes, their name is Legion, whom you, with the love of the lovely Legion. Christ in your heart and the patient goodness of your humanity, will have to care for, treat, watch 
Malt

and

hops.

Bronchial affections.

and spend yourself upon; but with the aids of modern science, with the skilled physician to direct you, with a large and brilliant medical literature to advise you, few will be the cases which you cannot relieve, and many are the cases that you will see with joy return to as perfect health as did this poor lunatic under the magnetic touch of Jesus, and who will gladly do as Jesus advised, "Go home to thy friends and tell them how great things the Lord hath done for thee, and hath had compassion on thee!"

We wish to encourage you with a few quotations of eminent physicians of many years' reputation and standing, regarding the uses of Malt Extract in the care of various diseases, both bodily and mental. You will be astonished, perhaps, to see how far malt and hops have entered into the confidence and good graces of those who have faithfully compared in their practice the various results of all kinds of preparations for the alleviation of symptoms.

Perhaps the most surprising is the general advocacy of malt extracts in tuberculosis, phthisic and bronchial affections, where cod-liveroil and whisky have been for so many years, and perhaps centuries, regarded as standard and unapproachable remedies and alleviators. Also in surgical work, where there are suppurating wounds and in affections of the joints, it was not in old times considered a good or necessary thing to use malt and hops as a remedial agent. The idea seemed useless and foreign to the sub- 
ject. But modern careful scientific analysis of their effect have declared emphatically for them as against other stimulants and nutrients. For instance, in the Basle Hospital, the malt extracts are coming greatly into favor in the cases where cod-liver-oil and similar emulsions have previously been used. In phthisic and other wasting diseases malt has been preferred for several years. They have found no reason to change back to the unpleasant and distasteful oils, which in old-fashioned ideas were the mendall and cure-all in consumption and other "lung troubles." The extract may be given from one to three times a day in doses of a wineglass, if it be The Best Tonic. The use of Pabst Malt Extract may be fully depended upon to do exactly what is expected, being palatable, strengthening, soothing, stimulating and never nauseating.

In Naphey's "Surgical Therapeutics," page 505 , we find "Malt extracts are very valuable adjuvants in the treatment of scrofula and tubercle. They improve the nutrition and often arrest the progress of disease. They accomplish the good results of stimulants without their injurious period of reaction and other baneful effects."

Bartholow says also: "As beers contain malt, so their nutritive value is greater than spirits or wines. An important constituent, the hop, being an aromatic bitter, the tonic and stomachic qualities of malt extracts are also greater than

Best

Tonic.

Naphey's.

Increase

the

appetite. their congers. They increase the appetite and 
Aids

digestion.

In

place

of

stimulants. favor the deposition of fat. They do not cause the alterations in the nervous centers that are produced by spirituous liquors." If beers are so well esteemed, the newer and more medicinal Malt Extract must of necessity be of more value in particular cases, and carry with it far greater power in far smaller quantities.

Wallace, in the "Annual of the Universal Medical Sciences," writes that "the inability to digest starch is one of the commonest forms of dyspepsia, and that the principle lying at the foundation of the use of malt is, that its diastase will aid in the digestion of starches. To accomplish this object, the malt should be given before meals. Taken before meals it supplies maltose in a very digestible form for immediate assimilation, and along with it furnishes diastase for absorption into the blood. Taken along with the food it becomes intimately mixed with the starches, and so aids in their digestion. As it may also be used to convert starch into sugar before it has been taken into the stomach, the author strongly recommends it in the place of stimulants in convalescence from prostrating i11ness." We would add that when the malt is scientifically mixed with hops, as in the Pabst Malt Extract, The Best Tonic, it has just twice the digestive power, twice the nutritive power and twice the stimulating power, while with this it adds nervous tone, giving sound sleep and invigoration which cannot be had by the use of malt alone. It serves as a most excellent sustainer and bracer. Besides these two essential 
qualities, we are forced to believe in another element in this combination, and that is the sedative quality, which makes it a most valuable therapeutic desideratum.

Every observing nurse knows that regularity in the bowels is one of the most important points in the elimination of disease, but we cannot have the proper medium between constipation and too much laxity without digestion of whatever is partaken. In exceedingly weak conditions, that which will digest itself and aid in digesting everything else in the stomach, is the prize of prizes.

The following is a list of the fevers which a nurse will in all probability attend in the course of his or her work: Catarrhal, Cerebro-Spinal, Congestive, Enteric, Hemorrhagic, Intermittent, Remittent, Nervous, Scarlet, Simple Continued, Typhoid, Typho-Malarial, Typhus, Yellow, Measles, Rubeola, Erysipelas, Small-Pox, Pneumonia, Pleurisy, Bronchitis and Insomnia. In all these malt will many times play an important part if given a chance. When the temperature is normal and the pulse is weak, then the Pabst Malt Extract comes into valuable use, combined with some good extract of beef in small quantities, frequently repeated. This will do more lasting good to the patient than anything else which can be done. Not one person in 100 will find any disagreement with the stomach or any part of the system. These fevers, which accom-

No

disagreement. pany or attend other diseases, or are an acute disease of themselves, afflict at least three-fourths

Elimination of disease.

\section{List}

of 
Aid

in curing.

In

acute maladies.

Acme

of

Malt

Extracts.

Samuel

E.

Milliken. of the sick people of the world, and there is seldom, among them all, a condition where a perfect Malt Extract would not be the very best nutriment which could be administered.

Malt extracts do not cure. Nobody claims that they will cure a scarlet fever, or small-poxno such ridiculous ideas have ever been suggested,-but we do not only suggest, but maintain, that Pabst Malt Extract will aid the patient, feed the patient, tone the patient and infuse new life and vigor, so that he can withstand an acute attack, and recover rapidly after the crisis.

"In acute maladies malt extracts are justly very much esteemed, as well as in chronic and wasting diseases, or when the system requires the most nutrition with the least wear of digestion. In surgical injuries, in cases where there is profuse and protracted suppuration, in prolonged lactation, in diseases of the joints, scrofula, phthisic and pneumonia, nothing can take the place of a well-prepared malt extract." A malt extract that has taken 100 points of perfection at the World's Fair, and given the first and pre-eminent place among the extracts of the whole world, must meet the requirement of being "well-prepared", and so Pabst Malt Extract is the acme of such productions for use in all the cases the author mentions.

Samuel E. Milliken, M. D., surgeon-in-chief of the New York Infirmary for Crippled Children; surgeon to Randall's Island Hospital, etc., in the course of an article entitled "Tubercular 
Joint Disease in Children," which appeared in La Revista Médico-Quirurgica, Feb., 1895, said:

"The great mistake so often made by the specialist is the concentration of all his forces on the particular part of the human economy in which he is most interested, while the general health is allowed to take care of itself. No class of cases require more detail in their general treatment than do these tubercular bone lesions. In all cases where suppurating sinuses have existed for any length of time, the digestive and assimilative powers are invariably weak, for which we should give reconstructives to compensate for the waste which has already taken place."

It is acknowledged by hundreds of equally careful physicians that there are no better reconstructives than the combination of malt and hops, which with the addition of beef-blood in any good form is the concentrated essence of life, strength and vitality. The cereal extracts in Pabst Malt are of the purest and brightest quality, as may be observed from the great gush of bubbling foam which spouts from the bottle upon opening, and the rich ruby color which sparkles like a gem,-the very sight of which is cheering and attractive to the sufferer and feeds the eye before it feeds and warms the stomach.

Another use to which, at home or elsewhere, The Best Tonic should be put, is the helping of the Epileptic patient. Few who suffer from this terrible "falling sickness," which comes on so unexpectedly, which is so dreadful in its present manifestations and so wasting and debilitating

Reconstruct.

Concentrated essence.

Falling sickness. 
Doctor

Frederick

Peterson.

Recommends

Malt

Extracts.

In

nervous depression. to body and brain as an after result, can know or dream what a fine effect a course of Pabst Malt Extract will produce. The fits will be less often, less serious, less prolonged, less severe in their results, and may possibly be stopped altogether. In an article on "The Treatment of Epilepsy," by Frederick Peterson, M. D., attending physician New York Hospital for Nervous and Epileptics; Neurologist to Randall's Island Hospitals; President of the Board of Managers of Craig Colony of Epileptics, etc., he says: "In regard to the patient's general physical health, each particular physical defect or disorder demands its appropriate remedial agent. But many cases require general upbuilding and tonic remedies for conditions of impaired nutrition, anæmia and nervous depression." . . $\mathrm{He}$ goes on to advocate the use of malt in a general way, and suggests that the terrible disease of Epilepsy is much reduced by the use of something in the system which builds, recuperates, produces light-heartedness, good sleep and nervous tone. This is simply, without saying it, advocating Pabst Malt Extract, The Best Tonic, for no other combination of malt and hops contains the powers to produce these results in perfection.

It is this very upbuilding and toning of the system which can be done pleasantly, perfectly, assuredly, by means of this palatable and rich blood-making extract, than which nothing better is found or chosen. Anæmia and nervous depression cannot exist in the physique fattened 
and exhilarated by The Best Tonic! A glass cannot be empty when it is full,- - and the tissues of the body fed and supported by hops and malt in so excellent a combination, will "bulge with fatness," like jolly old Falstaff.

The celebrated Dr. Graeme M. Hammond, of New York, in an article on Neurasthenia, observes: "In many cases the digestive organs fail to perform their functions properly, either because the digestive juices are not secreted in their proper proportion, or else chemical changes in their composition diminish or interfere with their activity. The free use of alcohol is always more or less injurious to the normal individual, but is particularly so to the neurasthenia patient. On the other hand, it has been my experience that small quantities of alcohol given with the heaviest meal frequently assist feeble digestion. More than this, it seems to dissipate for the time at least the depression and confusion which are so often prominent symptoms. It has therefore long been my custom to advocate the ingestion of a small quantity of alcohol at the dinner hour." In no form can a small quantity of alcohol be taken into the stomach with such good results as in the very small proportion contained in The Best Tonic, mingled, as it is, with all those constituents which go to make cheerfulness, aid assimilation, add nutriment and act as a pleasant bracer to the nerves.

Another writer says: "When wakefulness is due to cerebral anæmia, a glass of beer has always been recognized as one of the surest means

Dissipates depression. 
Produces satisfactory sleep.

Opium or

Difficult to treat. to produce satisfactory sleep, but far better than beer is The Best Tonic, especially to one chronically sleepless, as it gives greater nutrition and a warmth and glow to the whole system which, gently pervading the brain, allays excitement and induces drowsiness, until one drops off to slumber unconsciously."

One of the most important and trying cases which comes to the care and observation of the male nurse is the inebriate, the opium or morphine patient, the victim of the use of chloral or other narcotic or poisonous and irritating drugs, which, in the stage where a nurse is called in, are usually at the height of excitement, or stupidity or acute agony of mind and body.

To withdraw the irritating drug is perforce necessary, either to the full, or to a degree. During the withdrawal of opium a great variety of neurotic symptoms appear which are not only very distressing, but difficult to treat. The milder narcotics are aggravating in the transient relief which they bring, and spirits are often unpleasant to the taste, and, only when large doses are used, bring relief. The question often occurs, Is alcohol, in any form, a practical narcotic for these psychical disturbances? This is variously answered, but usually in the negative. Yet something must be given which will satisfy the inevitable demand of the stomach for stimulant and food-something that will allay the unspeakable hunger and thirst, heat and soreness which is driving the person to madness. Humanity will respond, even if pity fails, and the re- 
freshing, bracing, soothing extract of malt, containing every ingredient necessary to feed the abused organ, warm it, urge it to normal action, arouse appetite and hush the wearied mind to silence and slumber, will be your first thought.

The slang or vulgar term, "tapering off", often used by the victim of "a spree", means less and less of that "hard licquor" which is his bane, and eager as many men are to exchange health and sobriety for pain and intemperance, Pabst Malt Extract, The Best Tonic, will come as a God-given boon. Hundreds have been glad to admit and to recommend to unfortunate friends, the wonderful curative properties of this extract during that uncertain period when nature must either give up to delirium or death in utter despair, or creep back into life and sanity by some method not sufficiently well known. Hundreds have blessed the beneficent quickness with which appetite, sleep and peace have been restored, together with that brain power and nerve steadiness which enables the patient to resist further temptation, and once more stand erect in his restored manhood:

There are all sorts of lesser troubles of life where the patient adds to some chronic or acute disease a state of nervousness which at times seems almost beyond control, or aggravates the pain or fever by a restlessness and excitement that is far from normal. These conditions can be safely met in almost all cases by a judicious amount of The Best Tonic, which allays these

Curative properties.

Brain power.

Safely met. unusual or unexpected symptoms in a very few

Soothing

malt. 
Calm

the

irritation.

For yourself. minutes. A sedative without the least bad effect, an ease-bringer without the results which come from opium, morphine, chloral, chloroform, ether, lavender wine, or other highly resultant drugs, often used when a nurse is at her "wit's end", it will calm the irritation as nothing else will, without danger, nausea, loss of appetite, constipation, lethargy, sinking, or loss of consciousness, except in a natural and refreshing sleep.

An old and valued nurse from the Basle Hospital writes: "For yourself, after long watching, great fatigue, nervous strain, close care or debility from too close confinement at the bedside of your patient, when you cannot 'woo sweet slumber' do what you will, Pabst Malt Extract at once comes to mind, and is invaluable in all such conditions. A wineglass three or four times a day will drive away all lassitude, give new vigor and strength to carry on your work and help you to drop asleep the instant you lie down. Otherwise, if you allow yourself to 'run down' and go night after night without its beneficent aid, it will probably follow that you will be nursed yourseif instead of nursing." 


\section{Doints to Chink albout.}





\section{POINTS TO THINK ABOUT.}

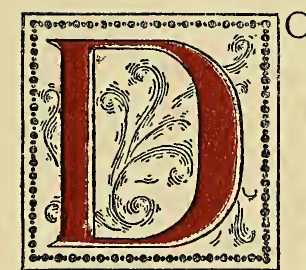

not read to the sick when you can tell it to them, and whether reading or talking let every word and syllable be slow, measured and distinct so that the patient may listen and Slow and comprehend with the least expenditure possible, for his strength is his life.

Holding the hand of the very sick and the dying is a comfort unspeakable to them, and if you are holding it and the spirit is passing away, do not release the grasp until the poor heart is at rest, for it gives the feeling of company, of sympathy, of help.

When near death the pulse runs up to one hundred and forty beats in a minute and faster and faster to the end when it ceases forever. The soft pulse as if a woolen string were vibrating under the finger is safe; but a pulse that pulse. beats with the tenseness of a thin wire, is full of danger.

Everyone ought to know how many times the pulse beats in a minute in repose, in health, for sometimes persons have a preternaturally fast or solw pulse in health, and in illness the 
The

pulse

beats.

Warmth.

Air.

Use

of

ice.

Mustard

plaster.

Fire.

Poultices. physician may make a fatal mistake unless he knows this. An infant's pulse is 130 a minute; at seven, 80. Up to threescore years it is about 70 a minute; a woman's is five or six more; at fourscore it declines to 60 in the normal person.

In the recovering from any sickness keep your patient abundantly and comfortably warm. Studiously avoid their taking any cold. Watch against over-exercise. Have them eat moderately of plain nourishing food with a good glass of The Best Tonic with each meal.

Remember that under all circumstances night air is as healthful as day air if the person is not too weak, hungry or chilly.

Ice as a remedy, eaten and swallowed in lumps, is the safest and best method of quenching great thirst in health or disease; pounded and applied in a half-filled bag is the quickest relief of inflammation of the brain or any part of the body; and in the form of the coldest water used as an injection, gives instant relief and speedy cure in all forms of diarrhoa and dysentery.

Mustard plasters are best made by simply, mixing the white of eggs with the mustard so as to make a paste; it is very powerful, but does not break the skin.

Whenever a patient feels that a shawl is comfortable in the room, you may be sure that the fire should be made or attended to.

The best poultices are those which keep moist the longest. Irish moss in inodorous, does not 
slip nor sour nor stain, and need not be renewed for eighteen hours.

In applying a cold water compress a dry impervious cloth, such as oiled silk, should cover the compress and extend an inch or more beyond it, so as to lay down flat on the skin and prevent the steam inside from escaping; this opens the pores of the skin. The next compress gives a shock or a check, followed by a reaction, acting also by the evaporation of the water carrying off the heat very rapidly through the instrumentality of the steam. Thus may intense inflammations and burning fevers be safely and gratefully cooled off without any medicinal means. Compresses are cold or hot, linen or woolen. With woolen apply hot water, with linen apply cold. If you wish to diminish the heat of the part, use the old. If there is no external appearance of heat and redness on the skin but an internal fever, use the hot. Take five or six thicknesses of linen or two or three of woolen. Change often and always put the oiled silk on too, so that the steam will be kept in.

Raw cotton bound well on sores and wounds and the surfaces of amputated parts, they having been well washed with camphorated spirits, is a better cure than any poultice, because the spirits kill those germs of disease which are always floating in the atmosphere, while the cotton is such a perfect filterer it is impossible for any of these corrupting and poisonous germs to reach the sore; hence it heals healthfully from the beginning. 
Boils.

Vaccinate.

Speediest remedy.

Laugh and grow fat.
If the feet are found cold in the bed, rub each one well and wrap up each one in a newspaper.

To be patient and thorough in all that one undertakes is to compel success in any calling.

Boils and carbuncles are put back by anointing with the gray mercurial ointments four times a day, thereby rapidly reducing the inflammation and pain.

Plunging a burned or scalded part in cold water instantly allays pain and in case of young children quiets the alarm and noise of crying, giving composure to attend in further ways.

The infant should be vaccinated within a month of birth, and if repeated at fourteen and a good mark left, it is an almost certain and perfect preventive of small-pox.

Many think they are ridding the sickroom of noisome odors by introducing a stronger one, as the burning of sugar on red-hot coals, which really but adds to the impurity of the air. The only perfect and the speediest remedy is to open the windows and doors to create a draught which shall carry the bad air out of the house and let it go skyward. Cover the patient's head wholly with a comforter or shawl, and if in cold weather let it remain so a few moments after the windows are closed.

Don't be melancholy, whatever you do. Find something to laugh about if you have to buy "Punch" and laugh to find there isn't a laughable thing in it! A sense of the ridiculous, a good laugh, has been known to turn a patient from disease to health. Keep up a jolly sense of 
pleasant expectation in the sufferer, who can't endure anybody about who looks like a walking funeral.

The marring of the beauty of the human face from small-pox is prevented by confinement to a very dark room, or by keeping out of the light. This may effectually be done by painting the vesicle with a camel's-hair brush dipped in honey four or five times a day, the last just before retiring at night; this not only excludes the action of the light but also that of the air, and keeps the parts moist, antagonizing fever, while allowing the escape of foul emanations.

A foreign substance is readily removed from the ear by looping a horsehair, dropping it into the ear, then turn till it catches and drawing it out gently. So you can get a cork out of a bottle with a string.

"The grandest maxim in modern medicine is: Sustain the Strength of the Patient." This can almost invariably be done by the use of a malt extract, which is the perfection of nutritious and digestible food, which never nauseates or causes distress, and which produces a lively warmth and glow which is the very element of this "grandest maxim." Pabst Malt Extract, The Best Tonic, is the best.

A great deal of the hacking, hemming, and coughing of invalids is nervous, purely nervous or from the force of habit, as is shown by the frequency when thinking about it and the comparative rarity when the person is so much engaged that there is no time to think about it.

To prevent pitting.

The ear.

Never nauseates.

To stop hacking. 
The consumptive. ic invalid, and his food should be supplemented and sustained with the Pabst Malt Extract, which seems to have been invented especially for his use, so beneficent are its results in the disease which, alas! is so prevalent. Always let the patient have a due amount of exercise in the open air every day and let him enjoy every cheerful thing going, sustaining his strength as far as possible by The Best Tonic. He has only so long to live, and should have your kindest indulgence.

It is the brooding over one disagreeable thing that fills our mad houses, it being the want of

Draw the mind away. breath, flesh and strength than almost any chronforce of character to draw the mind away from the dangerous topic. Add your force of character, your ingenuity, your invention, your
Try to compel the attention of a hacking patient to this idea.

The consumptive imperatively needs more stimulation to the person whom you are attending for any kind of monomania or lunacy. Make them work with their hands, play games, exercise out of doors and mentally indoors and do not let them have time to brood.

Many of the above hints are taken from an admirable little volume, by W. W. Hall, M. D., "How to Live Long." 


\section{Gardorsentents from the Medileal Profession.}

Providence, R. I.

For those who are troubled with nervous affections, in my practice of twelve years I have found nothing better.

DR. F. H. ROSCOE.

Philladelphia, Pa.

I have used the "Best Tonic" and am very well pleased with the results. I have prescribed it for several of my patients, and have had excellent results up to the present time, and will prescribe it in the future where I want a good tonic.

Fort Washington, Pa.

I have both prescribed the "Best Tonic" to my patients and used it in my own family for a number of years with the utmost satisfaction. Very truly yours, M. NEWBURY, M. D.

HANCOCK, Mich.

I think the "Best Tonic" is an excellent preparation, and am prescribing it to many cases with marked benefit.

Yours truly,

W. A. BURNHAM, M. D.

Middletown, Pa.

I have been prescribing your Malt Extract for the past six years. It is an excellent remedy and I can speak of it in the highest of terms. It does all it is claimed to do and is an excellent remedy for the aged.

I remain yours very truly,

DR. O. R. KLUGH.

Philadelphia, Pa.

As a galactagogue your "Best Tonic" is worthy of special mention. I used it in a case of a nervous, rather anæmic patient, who in her three previous pregnancies was unable to nurse her children, but by its use the mammary gland rapidly took on its function, and its secretion soon became large in quantity and of best quality. As a tonic I think it very good, and as a milkproducer I consider it without a rival. Very truly yours, U. GRANT HEIL, M. D.

Cleveland, O.

I consider the "Best Tonic" a very pure article and shall avail myself of the opportunity of recommending so excellent an article to my patients and others.

Yours very truly,

A. W. WHEELER, M. D. 
Cincinnati, O.

I have used the "Best Tonic" in a case of neurasthenia with great benefit to the patient. Yours, W. W. BAILEY, M. D.

Miamisburg, OHio.

Have been prescribing your "Best Tonic" since its introduction to the profession. It is an elegant reconstructive, especially indicated in mal-nutrition.

Respectfully, W. P. WEAVER, M. D.

Cambridge, O., December 7, 1895 .

I shall continue prescribing your Malt Extract, as it is an excellent tonic.

T. L. McQUAIDE, M. D.

HaNover, N. H.

Wife takes "Best Tonic" and thinks there is nothing to strengthen and support like it. FRANK HUNDLEY.

Carthage, N. Y.

A sample of your "Best Tonic" came into my office just as I had on my hands a case of exhaustion and nervous debility, for which it was necessary to find something that would act as a food for both the digestive and nervous system and tone the stomach to receive and assimilate natural food. His bowels were lax, and I confess I hesitated about giving him the Malt, but only for a moment. Something had to be done at once or a very useful man would be laid off from his business. I drew the cork and told him to put the bottle to his mouth and drink. $\mathrm{He}$ drank about half a glass and inside of ten minutes he said, "I feel better." His nervousness was almost entirely gone. "Drink more," said I. He did so. In half an hour he felt hungry, and he continued to improve, drank the whole bottle in the course of the day and by my advice another the next day and said he was well. I cannot say too much in its praise. It truly is "Best."

L. C. HUBBARD, M. D.

Atlanta, Ga.

I take much pleasure in acknowledging the benefit derived from your Malt preparation. Indeed, the good resulting from it in some cases has been such that I feel great confidence in prescribing it when indicated. Yours very truly, K. H. BOLAND, M. D., National Surgical Institute.

Sand Beach, Mich.

I gave the "Best Tonic" a trial on a child on which $I_{4}$ had tried most everything else without any benefit. The child was very anæmic and was run down to almost a skeleton, but after taking your "Best Tonic" for a week it began to improve rapidly and is to-day as sound, fat as any child can be. I then tried it on a lady who had typhoid fever, and convalescence was very 
slow. She wouldn't gain strength, although the fever had left her two weeks and four days up to day since she took "Best Tonic," and the result is really marvelous.

$$
\text { Respectfully yours, } \quad \text { P. O. WAGENER, M. D. }
$$

BALTIMORE, MD.

Your "Best Tonic" is undoubtedly an excellent preparation, and have employed it with gratifying results in cases of neurasthenia with deficient digestive tone, finding it has none of the injurious and disagreeable sequellæ of the medicinal wines.

\section{Waterbury, Conn.}

I have been a sufferer from dyspepsia for years. I gave your "Best Tonic" a trial and find that it is doing me a great deal of good. I intend to use it right along. Your "Best Tonic" deserves to be better known to the general public, because it is the "best" tonic in my experience, and I have tried a good many of them. Yours truly,

P. MEERLENDER.

Philadelphia, Pa.

I find Pabst Malt Extract to be of excellent quality, and on account of its purity and valuable tonic properties, I shall continue to recommend its use to my patients, and others.

$$
\text { Yours respectfully, CHAS. S. GAUNTT, M. D., }
$$

Late Prof. of Medical Chemistry in the Hahnemann Medical College of Philadelphia.

La Fayette, Ind.

Ever since your excellent "Best Tonic" has been placed upon the market my family has been a big consumer of this preparation. I have found it a grateful stimulant, appetizer, tissue builder and tonic. I consider it one of those very few preparations that really do all they claim to do, and therefore I unhesitatingly use it for my own family and recommend it to my patients.
Respectfully yours,
CHAS. HUPE, M. D. 


$\cos (\mathrm{sin}) \mathrm{Br}$

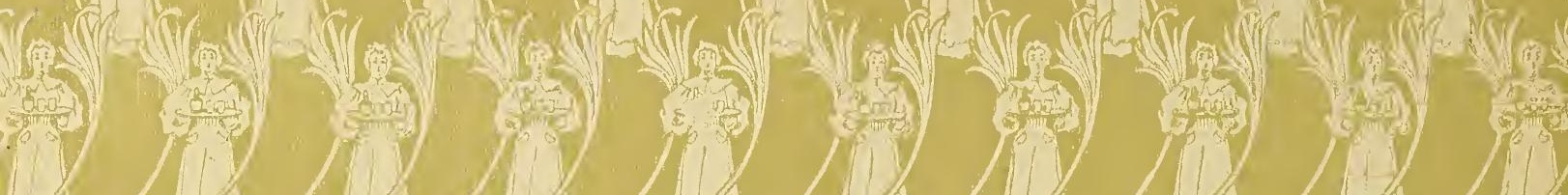

(1)

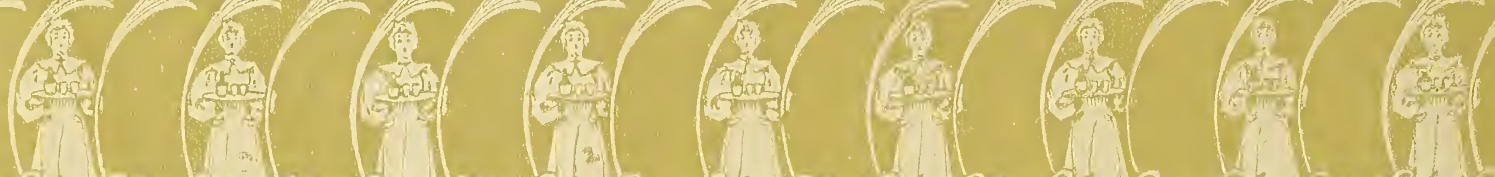

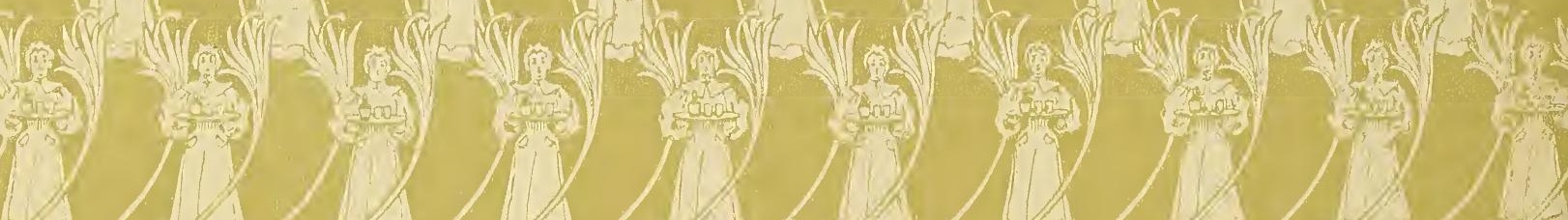

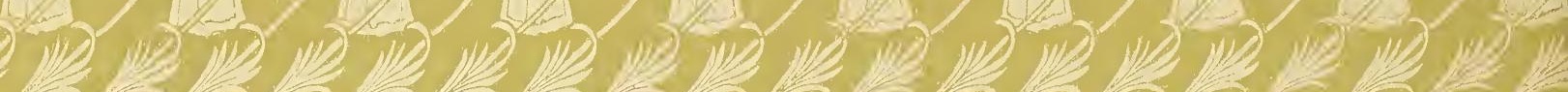

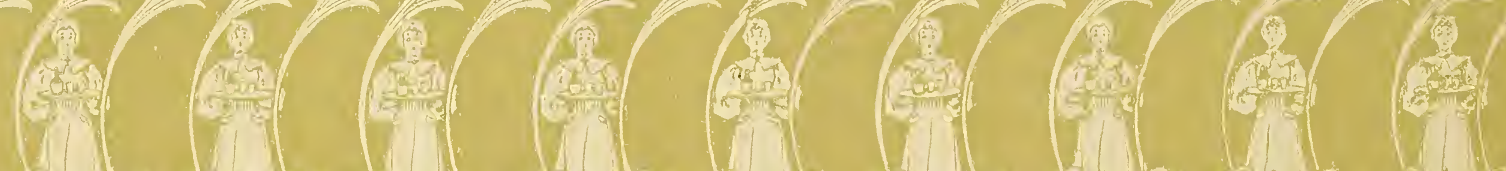

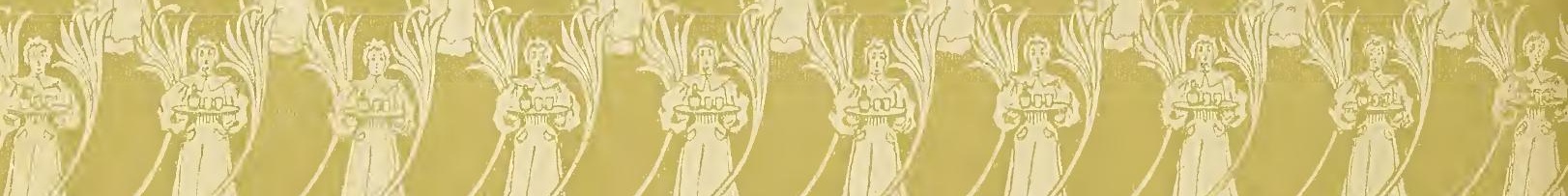

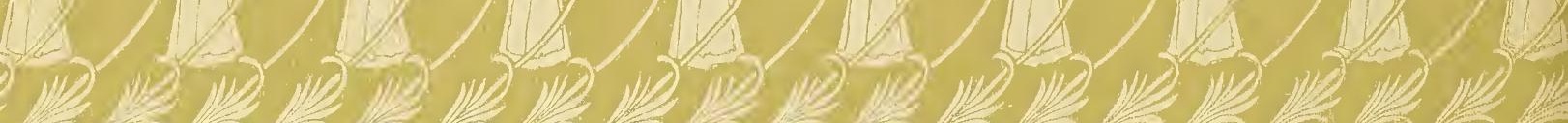

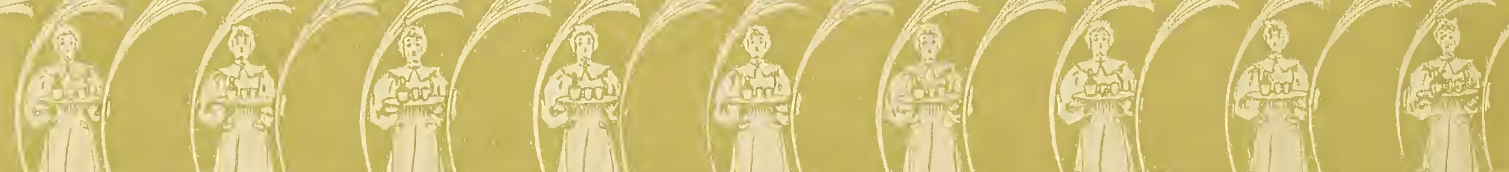

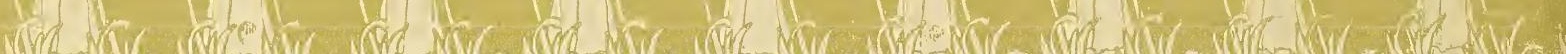

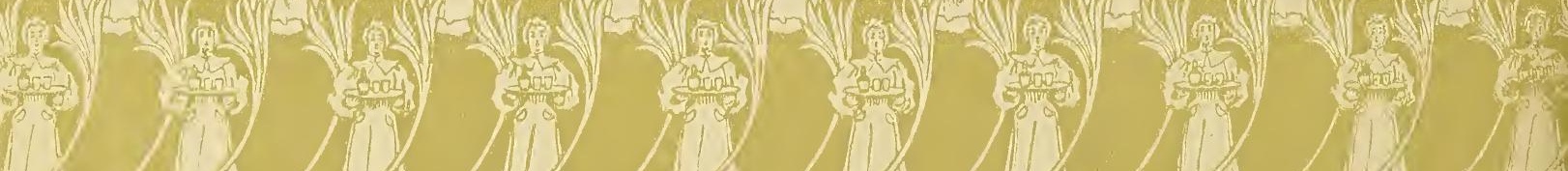

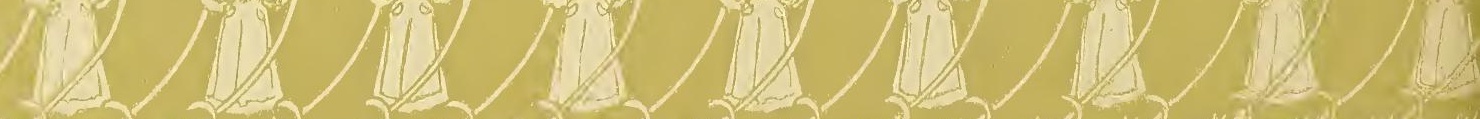

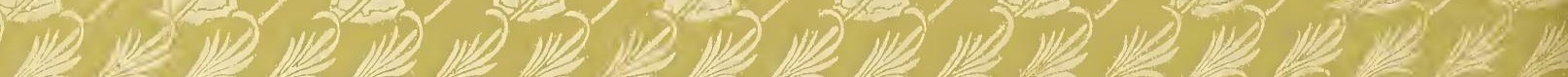

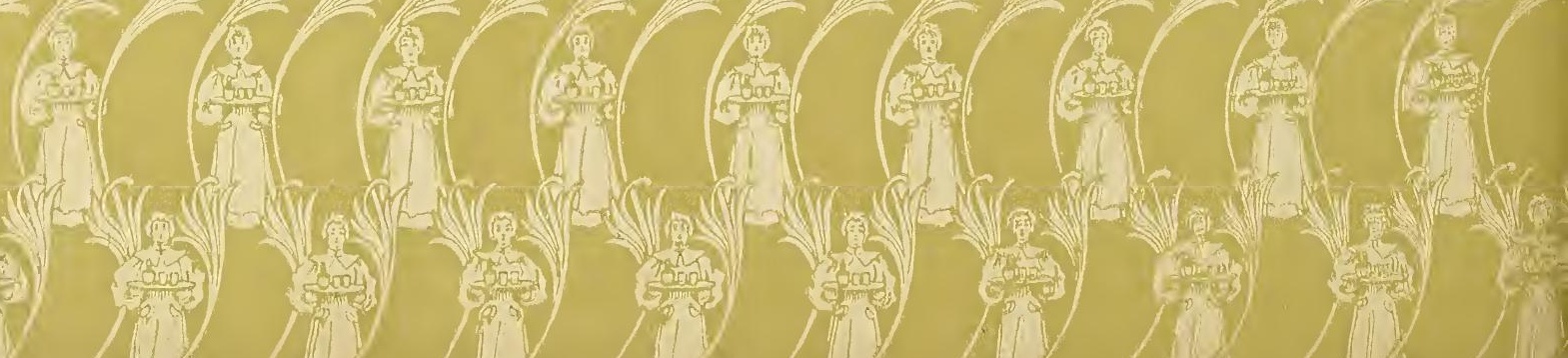


